Title:

2 Chromatin profiling of the repetitive and non-repetitive genome of the human fungal

Authors:

$5 \quad$ Robert Jordan Price ${ }^{1}$, Esther Weindling ${ }^{2}$, Judith Berman ${ }^{2}$ and Alessia Buscaino ${ }^{1 *}$

$8 \quad$ Running Title: Candida albicans chromatin profiling

$10{ }^{1}$ University of Kent, School of Biosciences, Kent Fungal Group, Canterbury Kent,

11 CT2 7NJ. UK

$12{ }^{2}$ Department of Microbiology and Biotechnology, George S. Wise Faculty of Life

13 Sciences, Tel Aviv University, Ramat Aviv, 69978, Israel

14 * To whom correspondence should be addressed. Tel: (+44) (0)1227824854; Email:

\title{
15 A.Buscaino@kent.ac.uk
}




\section{ABSTRACT}

18 Background

19 Eukaryotic genomes are packaged into chromatin structures with pivotal roles in

20 regulating all DNA-associated processes. Post-translational modifications of histone

21 proteins modulate chromatin structure leading to rapid, reversible regulation of gene

22 expression and genome stability which are key steps in environmental adaptation.

23 Candida albicans is the leading fungal pathogen in humans, and can rapidly adapt

24 and thrive in diverse host niches. The contribution of chromatin to $C$. albicans biology

25 is largely unexplored.

\section{Results}

27 Here, we harnessed genome-wide sequencing approaches to generate the first

28 comprehensive chromatin profiling of histone modifications (H3K4me ${ }^{3}, \mathrm{H} 3 \mathrm{~K} 9 \mathrm{Ac}$,

$29 \mathrm{H} 4 \mathrm{~K} 16 \mathrm{Ac}$ and $\gamma-\mathrm{H} 2 \mathrm{~A}$ ) across the $C$. albicans genome and relate it to gene

expression. We demonstrate that gene-rich non-repetitive regions are packaged in

canonical euchromatin associated with histone modifications that mirror their

transcriptional activity. In contrast, repetitive regions are assembled into distinct

chromatin states: subtelomeric regions and the rDNA locus are assembled into

canonical heterochromatin, while Major Repeat Sequences and transposons are

packaged in chromatin bearing features of euchromatin and heterochromatin.

Genome-wide mapping of $\gamma \mathrm{H} 2 \mathrm{~A}$, a marker of genome instability, allowed the

identification of potential recombination-prone genomic sites. Finally, we present the

first quantitative chromatin profiling in $C$. albicans to delineate the role of the expression. 
42 This study presents the first genome-wide chromatin profiling of histone

43 modifications associated with the $C$. albicans genome. These epigenomic maps

44 provide an invaluable resource to understand the contribution of chromatin to $C$.

45 albicans biology.

46 KEYWORDS: Candida albicans, Chromatin, Histone modifications, Human fungal

47 pathogen, Heterochromatin, Euchromatin, Epigenetics, Genome Instability, Sir2,

$48 \quad$ Set1

\section{BACKGROUND}

50 Packaging of genomes into chromatin is the key determinant of nuclear organization

$51[1,2]$. The basic unit of chromatin is the nucleosome, consisting of a histone octamer

52 of two molecules each of histone $\mathrm{H} 2 \mathrm{~A}, \mathrm{H} 2 \mathrm{~B}, \mathrm{H} 3$, and $\mathrm{H} 4$, around which 147 bp of

53 DNA are wrapped in almost two turns [3]. Histone proteins are subjected to a wide

54 variety of post-translational modifications, known as histone marks, that decorate

55 distinct chromatin regions [3]. Modification of chromatin structure controls a plethora

56 of nuclear processes including gene expression, DNA repair and DNA replication

$57[3,4]$. Consequently, genome-wide maps of histone modifications have been

58 instrumental in identifying functionally different regions of eukaryotic genomes $[5,6]$.

59 Gene-rich, non-repetitive DNA is associated with active histone marks, forming

60 euchromatin, a chromatin state permissive to transcription and recombination [7]. At

61 euchromatic regions, promoters of active genes are enriched in histone $\mathrm{H} 3$

62 trimethylated on lysine $4\left(\mathrm{H} 3 \mathrm{~K} 4 \mathrm{me}^{3}\right)$ and acetylated on lysine 9 (H3K9Ac), while

63 gene bodies are enriched in a different set of histone modifications, such as

64 acetylation of lysine 16 on histone H4 (H4K16Ac) [8-10]. In contrast, genomic

65 regions enriched in repetitive DNA and low in gene density are assembled into 
66 heterochromatin [7].These repetitive sequences (including tandem repeats,

67 transposable elements and gene families) are a threat to genome stability. At

68 repetitive elements, heterochromatin assembly promotes genome stability by

69 repressing deleterious recombination events $[7,11,12]$. Heterochromatin is devoid of

70 active histone marks (i.e. $\mathrm{H} 3 \mathrm{~K} 4 \mathrm{me}^{3}, \mathrm{H} 3 \mathrm{~K} 9 \mathrm{Ac}$ and $\mathrm{H} 4 \mathrm{~K} 16 \mathrm{Ac}$ ) and is enriched in

71 repressive histone marks such as methylation of lysine 9 on histone $\mathrm{H} 3$ (H3K9me)

72 and methylation of lysine 27 on histone H3 (H3K27me) [1].

73 While euchromatin structure is largely conserved across organisms, histone marks

74 associated with heterochromatic regions vary between organisms. For example, in

75 the model system Saccharomyces cerevisiae, heterochromatin is devoid of H3K9me

76 and H3K27me marks but nucleosomes are hypomethylated on H3K4 and

77 hypoacetylated on H3K9 and H4K16 [1,13]. Phosphorylation of serine 129 on

78 histone $\mathrm{H} 2 \mathrm{~A}$ (known as $\gamma-\mathrm{H} 2 \mathrm{~A}$ ) is enriched at heterochromatin regions in $S$.

79 cerevisiae, Schizosaccharomyces pombe and Neurospora crassa, independently of

80 the cell cycle stage [14-17]. Given that $\gamma-\mathrm{H} 2 \mathrm{~A}$ is a hallmark of DNA double strand

81 breaks, these findings suggest that heterochromatic regions are flagged for DNA

82 damage. In contrast, in human cells, phosphorylation of $\mathrm{H} 2 \mathrm{AX}$, a modification

83 functionally analogous to $\gamma-\mathrm{H} 2 \mathrm{~A}$, does not decorate heterochromatic regions $[18,19]$.

84 Chromatin modifications also play major roles in controlling genome stability by

85 dictating pathways of DNA repair. Indeed, choices of DNA repair pathways (i.e. Non

86 Homologous End Joining or Homologous Recombination) depend on the chromatin

87 state of the genomic region undergoing repair and extensive chromatin changes,

88 including $\gamma-\mathrm{H} 2 \mathrm{~A}$, are linked to repair of DNA breaks [20]. Consequently, in

89 unchallenged cells, $\gamma$-H2A mapping is used to identify unstable genomic regions

90 (named $\gamma$-sites) that are prone to intrinsic DNA damage and recombination [14]. 
91 Chromatin modifications are reversible and specific histone modifiers maintain or erase the histone modification state associated with different chromatin regions. Among these, histone acetyltransferases (HATs) and histone deacetylases (HDACs) respectively maintain and erase histone acetylation, while histone methyltransferases (HMTs) and demethylases (HDMs) are responsible for the methylation state of histones [2,3]. Chromatin regulation rapidly and reversibly alters gene expression and genome stability and can, therefore, have a major impact on environmental adaptation of microbial organisms that need to rapidly adapt to sudden environmental changes [21,22].

One such organism is the human fungal pathogen Candida albicans. C. albicans is a commensal organism that colonises the mouth, the skin, and the uro-intestinal and reproductive tracts of most individuals without causing any harm. However, $C$. albicans is also the most common causative agent of invasive fungal infections and systemic infections are associated with high mortality rates (up to 50\%) [23]. C. albicans is such a successful pathogen because it rapidly adapts and thrives in diverse host niches. The ability to switch among multiple specialised cell types, as well as its remarkable genome plasticity, is at the basis of $C$. albicans adaptation [24]. containing 6408 protein-coding genes, in addition to a large number of non-coding

111 RNAs [25-28]. The genome of C. albicans contains several classes of repetitive elements: telomeres/subtelomeres, the rDNA locus, Major Repeat Sequences (MRS) and transposable elements [29]. Telomeres are composed of tandemly repeating

$11423 \square$ bp units, while subtelomeres are enriched in long terminal repeats (LTR), 115 retrotransposons and gene families [29,30]. 
116 The rDNA locus consists of a tandem array of a $\sim 12 \square \mathrm{kb}$ unit repeated 50 to 200

117 times. Each unit contains the two highly conserved $35 \square \mathrm{S}$ and $5 \square \mathrm{S}$ rRNA genes that

118 are separated by two Non-Transcribed Spacer regions (NTS1 and NTS2), whose sequences are not conserved with other eukaryotes [29,31]. MRS loci are long tracts $(10-100 \square \mathrm{kb})$ of nested DNA repeats found on 7 of the $8 C$. 121 albicans chromosomes [29,32]. These repetitive domains, found in C. albicans and 122 in the closely related species $C$. dubliensis and $C$. tropicalis, are formed by large 123 tandem arrays of $2.1 \square \mathrm{kb}$ RPS unit flanked by non-repetitive HOK and RBP-2 124 elements. Each RBP-2 element contains a protein-coding gene, FGR6, important for 125 morphological switches [32,33].

126 Several classes of retrotransposons are present in the $C$. albicans genome including 12716 classes of LTR retro-transposons (Tca1-16) and Zorro non-LTR retrotransposons 128 that are present in 5-10 copies per cell, dispersed along the chromosomes. Among 129 those, Tca2, Tca4, Tca5, Zorro-2 and Zorro-3 are capable of transposition [34-36]. 130 The C. albicans genome is remarkably plastic, and natural isolates exhibit a broad spectrum of genomic variations including Loss of Heterozygosity (LOH) events, chromosome rearrangements and aneuploidy [37]. Evolution experiments and

133 analyses of clinical isolates have demonstrated that repetitive elements are 134 hypermutable sites of the $C$. albicans genome and are prone to high rates of 135 recombination $[37,38]$.

136 Several studies have demonstrated that regulation of chromatin structure plays 137 critical roles in regulating $C$. albicans gene expression and genome instability [39138 42]. However, comprehensive profiling of histone modifications across the whole $C$. 139 albicans genome is still lacking. Generation of these epigenomic maps will be 
essential to truly understand the impact of chromatin regulation to C. albicans adaptation and development of virulence traits.

In this study, we used chromatin immunoprecipitation with massively parallel sequencing (ChIP-seq) technology to establish the first comprehensive genome-wide map of $C$. albicans histone modifications (H3K4me ${ }^{3}, \mathrm{H} 3 \mathrm{~K} 9 \mathrm{Ac}, \mathrm{H} 4 \mathrm{~K} 16 \mathrm{Ac}$ and $\left.\gamma \mathrm{H} 2 \mathrm{~A}\right)$, marking euchromatic, heterochromatic regions and potential recombination-prone unstable sites. Genome-wide mapping of RNA Polymerase II (RNAPII) and transcriptome expression profiling allowed us to unveil the link between histone modification states and transcriptional activity. We demonstrate that specific chromatin states are associated with the repetitive and non-repetitive $C$. albicans genome. While gene-rich regions are associated with active chromatin marks mirroring their transcriptional state, different types of repetitive elements are assembled into distinct chromatin types. Finally, we present the first $C$. albicans quantitative ChIP-seq (q-ChIP-seq) methodology that has permitted us to elucidate the roles of the HDAC Sir2 and the HMT Set1 in shaping the chromatin state of $C$. albicans genome and regulating gene expression.

\section{RESULTS}

\section{Genome-wide histone modification profiling in C. albicans}

The C. albicans genome contains two homologous pairs of divergently transcribed histone $\mathrm{H} 2 \mathrm{~A}$ and $\mathrm{H} 2 \mathrm{~B}$ genes, and histone $\mathrm{H} 3$ and $\mathrm{H} 4$ genes in addition to a single histone H3 gene (Fig S1 A). Sequence alignment demonstrated that the frequently modified amino acid residues H3K4, H3K9, H4K16 and H2AS129 are conserved in C. albicans (Fig S1 B).

To explore the chromatin signature of $C$. albicans repetitive and non-repetitive regions, we globally mapped the genomic locations of $\mathrm{H} 3 \mathrm{~K} 4 \mathrm{me}^{3}$, H3K9Ac, H4K16Ac 
and $\gamma \mathrm{H} 2 \mathrm{~A}$ by performing Chromatin ImmunoPrecipitation followed by high-throughput sequencing (ChIP-seq). Since nucleosomes are not equally distributed across genomes, we accounted for nucleosome occupancy by performing genome-wide profiling of unmodified histone $\mathrm{H} 3$ and histone H4. Finally, to correlate specific histone modification profiling with transcriptional activity, we mapped RNA polymerase II (RNAPII) occupancy genome-wide. In parallel, we performed transcriptome analysis by strand-specific RNA sequencing (RNA-seq) to profile gene expression levels.

For all samples, ChIP-seq was performed from C. albicans wild-type (WT) cells grown in standard laboratory growth conditions (YPAD $30^{\circ} \mathrm{C}$ ) using antibodies specific for modified or unmodified histones. Input (I) and Immunoprecipitated samples (Ip) were sequenced using the Illumina HiSeq2000 platform (single-end 50 bp reads; average coverage: 28x; Table S2, Dataset S1) and aligned to a custom haploid version of Assembly 22 of the C. albicans genome [25]. Unmodified histone H3 occupancy showed a strong positive correlation with histone H4 occupancy (Pearson correlation coefficient $r=0.97$ ), with the exception of centromeric regions where the histone $\mathrm{H} 3$ variant $\mathrm{Cse} 4^{\mathrm{CENP}-\mathrm{A}}$ replaces histone $\mathrm{H} 3$ (Fig $1 \mathrm{~A}, 1 \mathrm{C}$ and S2).

Furthermore, RNAPII occupancy showed a positive correlation with gene expression levels (Pearson correlation coefficient $r=0.72)$ (Fig 1B).

\section{H3K4me ${ }^{3}$, H3K9Ac and H4K16Ac mark C. albicans active genes}

To delineate the chromatin signature of protein-coding C. albicans genes, enrichment profiles for each histone modification were compared to histone $\mathrm{H} 4$.

Differential enrichment testing using DESeq2 allowed the identification of regions with statistically significant enrichment or depletion for particular histone marks compared to histone $\mathrm{H} 4$. We annotated these loci by proximity to annotated protein- 
coding genes and non-coding RNAs [25-27]. For RNAPII, aligned reads from ChIP

(IP) samples were normalised to aligned reads from the matching input (I) sample.

Metagene analyses demonstrate that, as expected, RNAPII is enriched across all gene bodies while unmodified histone $\mathrm{H} 3$ is not significantly enriched or depleted relative to unmodified histone $\mathrm{H} 4$. In contrast, $\mathrm{H} 3 \mathrm{~K} 4 \mathrm{me}^{3}$ and $\mathrm{H} 3 \mathrm{~K} 9 \mathrm{Ac}$ are more prominent at the transcriptional start site (TSS) and 5' regions of genes, and H4K16Ac is enriched at gene bodies. (Fig 2A).

To further explore the relationship between chromatin modifications and gene transcriptional states, we grouped all genes into four sets based on expression level (no expression, low expression, medium expression and high expression) as revealed by RNA-seq analysis (Fig S3). Enrichment profile plots of the levels of histone modifications for each of these gene sets demonstrated that $\mathrm{H} 3 \mathrm{~K} 4 \mathrm{me}^{3}$, $\mathrm{H} 3 \mathrm{~K} 9 \mathrm{Ac}$ and H4K16Ac levels are very low at genes with low transcription rates. Levels of all modifications increase with increased gene expression reaching a maximum at highly transcribed genes (Fig 2B).

Therefore, in C. albicans, $\mathrm{H} 3 \mathrm{~K} 4 \mathrm{me}^{3}, \mathrm{H} 3 \mathrm{~K} 9 \mathrm{Ac}$ and $\mathrm{H} 4 \mathrm{~K} 16 \mathrm{Ac}$ correlate with gene transcription; $\mathrm{H} 3 \mathrm{~K} 4 \mathrm{me}^{3}$ and $\mathrm{H} 3 \mathrm{~K} 9 \mathrm{Ac}$ are more enriched at the $5^{\prime}$ of a gene and H4K16Ac at the gene bodies.

$\gamma-H 2 A$ is enriched at convergent genes and in proximity of DNA replication origins

Having established that different regions of the $C$. albicans genome are marked by different chromatin modifications depending on their transcriptional state (Fig 2), we sought to systematically map the genome-wide profile of $\gamma \mathrm{H} 2 \mathrm{~A}$ ( $\gamma$-sites) in cycling undamaged cells, as this is a useful method to identify recombination-prone unstable sites [14]. Genome-wide ChIP-seq of $\gamma \mathrm{H} 2 \mathrm{~A}$ identified $168 \gamma$-sites where $\gamma \mathrm{H} 2 \mathrm{~A}$ is 
enriched compared to histone H4 (Dataset S1). C. albicans $\gamma$-sites are different from the $\gamma \mathrm{H} 2 \mathrm{~A}$-domain caused by irrecoverable DSBs as $\gamma$-sites have generally a single

217 peak of enrichment and they are shorter (average length $850 \mathrm{bp}$ ) than the 50-kb

218 length of the that $\gamma \mathrm{H} 2 \mathrm{~A}$ domain surrounding DSBs [44].

219 Analysis of $\gamma$-sites indicates that they are present at three classes of genomic loci: (i)

220 longer genes that are often convergent, (ii) origins of replication and (iii) subtelomeric

221 regions (discussed below) (Fig 3A and 3B).

222 At convergent genes, $\gamma \mathrm{H} 2 \mathrm{~A}$ enrichment is detected at both the gene bodies and

223 intergenic regions, and no correlation was detected between gene expression levels

224 and $\gamma \mathrm{H} 2 \mathrm{~A}$ occupancy. Although we did not observe any correlation between $\gamma$-sites

225 and histone H3 occupancy (Pearson Correlation $r=0.062), \gamma$-sites are more likely to

226 mark genomic regions that are acetylated on $\mathrm{H} 4 \mathrm{~K} 16$ and $\mathrm{H} 3 \mathrm{~K} 9$ (Pearson correlation

$227 \quad r=0.461$ and 0.276 , respectively). We also detect a weak negative correlation

228 between $\gamma \mathrm{H} 2 \mathrm{~A}$ occupancy and $\mathrm{H} 3 \mathrm{~K} 4 \mathrm{me}^{3}$ (Fig 3C).

\section{The chromatin state of the C. albicans repetitive genome}

230 Having determined the chromatin marks associated with C. albicans coding genes,

231 we analysed the chromatin state of the $C$. albicans repetitive genome focusing on

232 the major classes of DNA repeats: subtelomeric regions, the rDNA locus, MRS

233 repeats and transposable elements (LTR and non-LTR retrotransposons). Sequence

234 analysis of these elements can be problematic because of incomplete sequencing

235 and their repetitive nature [25,29]. To estimate the chromatin modification state of

236 these loci, we adopted a method previously applied to $S$. cerevisiae repeats and

237 assumed that each repeat contributes equally to read-depth [45]. Consequently,

238 reads that could not be uniquely mapped to one location were randomly assigned to

239 copies of that repeat. 
240 To investigate the chromatin state associated with the 16 subtelomeric regions in $C$.

241 albicans, we analysed the ChIP-seq datasets in the 20-kb terminal regions of each

242 chromosome arm. At these locations, occupancy of unmodified histone H3 was

243 similar to histone H4 occupancy (Fig 4A, S4 and S5). In contrast, we detected large

244 domains of chromatin that are hypomethylated on H3K4 and hypoacetylated on

245 H3K9 and H4K16 (Fig 4A, S4 and S5). However, the H3K4 methylation and

$246 \mathrm{H} 3 \mathrm{~K} 9 / \mathrm{H} 4 \mathrm{~K} 16$ acetylation state of subtelomeres is not uniform as patches of high

$247 \mathrm{H} 3 \mathrm{~K} 4 \mathrm{me}^{3}, \mathrm{H} 3 \mathrm{~K} 9 \mathrm{Ac}$ and H4K16Ac are detected within each subtelomere (Fig 4A, S4

248 and S5). We detected statistically significant $\gamma \mathrm{H} 2 \mathrm{~A}$ enrichment at 13/16 subtelomeres

249 (Fig 4A, S4 and S5). We suspect that absence of $\gamma$-sites at ChrRR, Chr1R and Chr7L

250 subtelomeric regions is due to incomplete genome assembly [25,29]. Subtelomeric

$251 \gamma \mathrm{H} 2 \mathrm{~A}$ enrichment is not uniform but present at distinct peaks within each

252 subtelomere, which largely associate with hypoacetylated and hypomethylated

253 chromatin (Fig 4A, S4 and S5).

254 Analysis of chromatin modifications associated with the rDNA locus demonstrate that

255 the NTS1 and NTS2 regions are assembled into a chromatin structure resembling

256 heterochromatin where nucleosomes are hypomethylated on H3K4 and

257 hypoacetylated on H3K9 and H4K16 (Fig 4B). These findings are consistent with our

258 published results demonstrating that these regions are assembled into

259 transcriptionally silent heterochromatin [46]. Intriguingly, we detected two $\gamma$-sites at

260 convergently transcribed genes surrounding the rDNA locus (Fig 4B).

261 This analysis also reveals that MRS repeats and retrotransposons (LTR and non-

262 LTR) are associated with chromatin that is largely hypomethylated on H3K4 (Fig 4C,

263 4D). In contrast, H3K9Ac and H4K16Ac are similar to histone H4 levels (Fig 4C, 4D). 
264 We did not detect any statistically significant enrichment of $\gamma-\mathrm{H} 2 \mathrm{~A}$ at either MRSs or

265 retrotransposons.

266 Therefore, different $C$. albicans repetitive elements are associated with distinct

267 chromatin states. Repetitive regions are more likely to be hypomethylated on H3K4,

268 but are neither hypoacetylated on H3K9 and H4K16 nor enriched for $\gamma-\mathrm{H} 2 \mathrm{~A}$.

The HDAC Sir2 governs the hypoacetylated state associated with C. albicans rDNA locus and subtelomeric regions

271 We have previously shown that, in $C$. albicans, the histone deacetylase Sir2 272 maintains the low level of H3K9Ac associated with the NTS regions of the rDNA 273 locus [46]. To assess the role of the HDAC Sir2 in maintaining acetylation levels 274 across the C. albicans genome, we performed H3K9Ac and H4K16Ac ChIP-seq 275 analyses in WT and sir2 $\Delta / \Delta$ strains.

276 Traditional ChIP-seq are not inherently quantitative as it allows comparison of protein 277 occupancies at different positions within a genome but it does not allow direct comparisons between samples derived from different strains [47-49]. To overcome this issue, we adapted C. albicans to a quantitative ChIP-seq (q-ChIP-seq) 280 methodology [47-49]. To this end, WT and sir2 $\Delta / \Delta$ were spiked-in, at the time of 281 fixation, with a single calibration sample from S. cerevisiae (Fig 5A). S. cerevisiae genome is a desirable exogenous reference for $C$. albicans cells because its genome is well studied and has a high-quality sequence assembly [50]. Moreover, reads originating from $C$. albicans or $S$. cerevisiae can be easily separated at the analysis level and our experiments reveal less than $2 \%$ of the total number of reads cannot be uniquely mapped (Table S2). Finally, histone proteins are well conserved 
antibody is likely to immunoprecipitate $C$. albicans and $S$. cerevisiae chromatin with the same efficiency.

The q-ChIP-seq analyses identify only two regions of the $C$. albicans genome with increased H3K9Ac and H4K16Ac levels: subtelomeric regions and the NTS region of the rDNA locus (Fig 5B, 5C, S6, S7 and Dataset S1). Deletion of SIR2 does not lead to increased histone acetylation levels at euchromatic regions or at other repetitive elements such as MRS and retrotransposons (Dataset S1). In agreement with these findings, the majority (83\%) of gene expression changes observed in sir2 $\Delta / \Delta$ cells occur at the rDNA locus and subtelomeric regions (Fig 5B, 5C, Dataset S1 and [46]) We conclude that the $C$. albicans HDAC Sir2 acts exclusively at two genomic regions: the rDNA locus and subtelomeric regions. Our findings are consistent with the hypothesis that Sir2-mediated histone deacetylation represses gene expression at these locations.

\section{Set1-dependent methylation of H3K4 impacts gene expression differentially at} different repeats

Our data demonstrates that $C$. albicans repetitive elements are associated with chromatin that is hypomethylated on H3K4. However, at these regions, H3K4 methylation is not completely ablated as pockets of $\mathrm{H} 3 \mathrm{~K} 4 \mathrm{me}^{3}$ are detected (Fig 4). In S. cerevisiae and S. pombe, the H3K4 methyltransferase Set1 has been implicated in both gene repression and activation [51-56]. S. cerevisiae Set1 also maintains the transcriptional silencing associated with heterochromatic regions such as the telomeres and the rDNA locus [51-56]. C. albicans Set1 is important for efficient yeast-to-hyphae switching but its function in regulating chromatin structure and gene expression is unknown [57]. 
312 To gain insights into the role of $C$. albicans Set1, we performed H3K4me ${ }^{3}$ q-ChIP-

313 seq and RNA-seq analyses of WT and set1 $\Delta / \Delta$ strains. C. albicans Set1 clearly plays

314 a major role in maintaining chromatin structure as 6846 loci, scattered throughout the

315 genome, have a statistically significant reduction of $\mathrm{H} 3 \mathrm{~K} 4 \mathrm{me}^{3}$ in $\operatorname{set} 1 \Delta / \Delta$ compared

316 to WT strain (Fig 6A and Dataset S1). RNA-seq analysis reveals that Set1 regulates

317 gene expression both positively and negatively, as genes with a reduced $\mathrm{H}_{3} \mathrm{~K} 4 \mathrm{me}^{3}$

318 pattern can be either upregulated (2320 genes/ ncRNAs) or downregulated (3184

319 genes/ ncRNAs) in set1 $\Delta / \Delta$ compared to WT (Fig 6A and Dataset S1). Analyses of

320 the $\mathrm{H} 3 \mathrm{~K} 4 \mathrm{me}^{3}$ pattern and gene expression levels associated with repetitive elements

321 demonstrates that Set1 has distinct roles at different repeats. At subtelomeric

322 regions and the rDNA locus, deletion of the SET1 gene leads to the reduced

$323 \mathrm{H} 3 \mathrm{~K} 4 \mathrm{me}^{3}$ levels and is accompanied by the down-regulation of associated genes

324 (Fig 6B, 6C and S8). In contrast, the reduced $\mathrm{H} 3 \mathrm{~K} 4 \mathrm{me}^{3}$ pattern associated with MRS

325 repeats in the set1 $\Delta / \Delta$ strain leads to increased expression of coding and non-coding

326 RNAs originating from MRS repeats (Fig 6D). Finally, deletion of SET1 leads to

327 decreased $\mathrm{H} 3 \mathrm{~K} 4 \mathrm{me}^{3}$ at retrotransposons without a significant impact on expression

328 of retrotransposon-associated coding and non-coding RNAs.

329 We conclude that Set1 is the major H3K4-methyltransferase in C. albicans playing a 330 key role in controlling chromatin structure and gene expression. Importantly, our 331 analysis reveals that although deletion of SET1 results in decreased H3K4 332 methylation across all repetitive elements, Set1 influences gene expression 333 differentially at each repetitive element.

\section{DISCUSSION}

335 Here, we present the first comprehensive chromatin profiling of histone modifications 336 associated with the $C$. albicans genome. Furthermore, we present the first $C$. 
337 albicans quantitative ChIP-seq to delineate the role of the chromatin modifiers Sir2

338 and Set1 in C. albicans.

The chromatin state of the C. albicans repetitive and non-repetitive genome

340 In all organisms, gene-rich genomic regions are associated with a histone

341 modification pattern mirroring their transcriptional state where $\mathrm{H}_{3} \mathrm{~K} 4 \mathrm{me}^{3}$ and $\mathrm{H} 3 \mathrm{~K} 9 \mathrm{Ac}$

342 are enriched at active gene promoters and H4K16Ac is localised at gene bodies of

343 expressed genes $[9,10]$. Our first objective was to obtain "proof of concept"

344 epigenomic maps of chromatin modifications associated with gene rich regions of the

345 C. albicans genome. A robust histone modification profiling relies on (i) the use of

346 antibodies that recognise modified histones with high specificity and (ii) the use of

347 appropriate biological controls. Specificity of antibodies used in this study has been

348 tested in S. pombe or S. cerevisiae histone mutants lacking the modifiable amino

349 acid (H3K9, H4K16, H2AS129) [14,58]. To distinguish between nucleosome

350 occupancy and depletion/enrichment of specific histone modifications ChIP seq

analyses was also performed using antibodies recognising unmodified histone H3

and $\mathrm{H} 4$. This is an important control that should be included in all studies aimed to analyse chromatin modification genome wide.

Our results confirm the validity of our experimental approach and conform to the chromatin pattern reported in other organisms by showing that active genes, associated with high levels of RNA Pol II, are assembled into canonical euchromatin where $\mathrm{H} 3 \mathrm{~K} 4 \mathrm{me}^{3}$ and $\mathrm{H} 3 \mathrm{~K} 9 \mathrm{Ac}$ are associated with promoters and $\mathrm{H} 4 \mathrm{~K} 16 \mathrm{Ac}$ is enriched at gene bodies. We conclude that in $C$. albicans, as in other organisms, a specific histone modification pattern is predictive of active transcription. 
are packaged into chromatin resembling the heterochromatic structure of other organisms, like the budding yeast $S$. cerevisiae, lacking H3K9me/H3K27me systems [45]. These findings are in agreement with our previous study demonstrating that the rDNA locus and subtelomeric regions are able to silence embedded marker genes, which is a hallmark of heterochromatic regions [46]. In contrast, we find that $C$. albicans retrotransposons and MRS repeats are assembled into a distinct chromatin state where nucleosomes are hypomethylated on $\mathrm{H} 3 \mathrm{~K} 4 \mathrm{me}^{3}$, but also acetylated on $\mathrm{H} 3 \mathrm{~K} 9$ and $\mathrm{H} 4 \mathrm{~K} 16$. Analyses of clinical isolates and in vivo evolution experiments have demonstrated that, in the host, MRSs and transposons are recombination hotspots as they are known sites of translocations [32,38,59]. Given the key roles of chromatin in regulating genome stability, it will be important to investigate whether the chromatin packaging of MRS and transposons regulates genome stability.

\section{¡H2A decorates $C$. albicans heterochromatic regions and potential}

recombination-prone unstable sites

The genome-wide $\gamma$-H2A profiling performed in this study reveals that this histone modification, a hallmark of DNA damage, is enriched at heterochromatic regions assembled into hypoacetylated chromatin that is also hypomethylated on H3K4. This is similar to observations in other fungal organisms where $\gamma$-H2A decorates heterochromatic regions [14-17]. In contrast, we did not detect any significant enrichment of $\gamma-\mathrm{H} 2 \mathrm{~A}$ at other repetitive elements such as MRS repeats and transposable elements. This is surprising because, in the host, MRS repeats are recombination hot-spots $[32,38]$ and therefore a place where DSBs might be expected to accumulate. C. albicans genome instability is increased under hostrelevant stresses $[60,61]$ and therefore we propose that the recombination potential of MRSs is unlocked following exposure the specific host niche stresses. 
387 Finally, we detected 168 additional $\gamma$-sites located in proximity of origins of replication

388 or convergent genes that are often long. DNA replication origins are known

389 replication fork barriers in many organisms and read-through transcription of

390 convergent genes can also cause genome instability by, for example, R-loop

391 formation [62]. Therefore, we propose that the $\gamma$-sites identified in this study

392 represent novel recombination-prone unstable sites of the C. albicans genome.

The role of the histone deacetylase Sir2 and the histone methyltransferase

\section{Set1 in controlling the C. albicans epigenome}

395 We present the first quantitative ChIP-seq in C. albicans that has allowed us to

396 delineate the roles of the histone modifying enzymes Sir2 and Set1. We demonstrate

397 that Sir2 maintains the hypoacetylated state of heterochromatic regions associated

398 with the rDNA locus and subtelomeric regions. Sir2 deacetylation at these loci is

399 linked to gene repression as shown by RNA-seq analysis. In contrast, we find that

400 deletion of Sir2 does not lead to increased histone acetylation and gene expression

401 at other genomic regions. Two possible scenarios could explain these findings: ( $I$ )

402 Sir2 is specifically targeted to subtelomeres and the rDNA locus or (ii) other histone

403 deacetylases act redundantly to Sir2 regulating hypoacetylation and gene expression

404 at other genomic locations.

405 We present evidence demonstrating that the HMT Set1 is a major contributor to

406 chromatin structure in C. albicans. Indeed, deletion of SET1 leads to an almost

407 complete ablation of H3K4 methylation and is linked to extensive gene expression

408 changes. This demonstrates that $C$. albicans Set1 is the major H3K4

409 methyltransferase. It is particularly intriguing that deletion of SET1 leads to

410 decreased $\mathrm{H} 3 \mathrm{~K} 4 \mathrm{me}^{3}$ at all known repeats, yet its effect on gene expression can be 
411 the opposite. Indeed, we demonstrate that at the rDNA locus and subtelomeric

412 regions Set1 represses gene expression while it activates gene expression at MRS

413 repeats. Further studies will untangle the role of Set1 at different genomic regions.

\section{CONCLUSIONS}

415 In this study we present the first epigenomic map of histone modifications associated

416 with the $C$. albicans genome. Given the key role of chromatin in regulating $C$.

417 albicans biology, the data generated in this study provide an invaluable resource to a

418 better understanding of this important human fungal pathogen.

\section{METHODS}

\section{Yeast growth and manipulation}

421 Strains used in this study are listed in the Table S1. Yeast cells were cultured in

422 YPAD broth containing 1\% yeast extract, $2 \%$ peptone, $2 \%$ dextrose, $0.1 \mathrm{mg} / \mathrm{ml}$

423 adenine and $0.08 \mathrm{mg} / \mathrm{ml}$ uridine at $30^{\circ} \mathrm{C}$.

\section{$424 \quad$ Antibody Information}

425 The following antibodies were used in this study: anti-H2AS129p (Millipore; Cat No:

426 07-745-I), anti-H3 (Abcam; Cat No: ab1791), anti-H4 (Millipore; Cat No: 05-858),

427 anti-H3K4me3 (Active Motif; Cat No: 39159), anti-H3K9ac (Active Motif; Cat No:

428 39137), anti-H4K16ac (Active Motif; Cat No: 39167), and anti-RNA Polymerase II

429 (BioLegend; Cat No: 664903).

\section{ChIP-seq}

431 Chromatin immunoprecipitation with deep-sequencing (ChIP-seq) was performed as 432 follows: $5 \mathrm{ml}$ of an overnight culture grown in YPAD was diluted into fresh YPAD and 433 grown until the exponential phase $\left(\mathrm{OD}_{600}=0.6-0.8\right) .20 \mathrm{OD}_{600}$ units of cells were 434 fixed with $1 \%$ formaldehyde (Sigma) for 15 minutes at room temperature. Reactions 
435 were quenched by the addition of glycine to a final concentration of $125 \mathrm{mM}$. Cells

436 were lysed using acid-washed glass beads (Sigma) and a DisruptorGenie (Scientific

437 Industries) for four cycles of 30 minutes at $4^{\circ} \mathrm{C}$ with 5 minutes on ice between cycles.

438 Chromatin was sheared to $200-500$ bp using a BioRuptor sonicator (Diagenode) for

439 a total of 20 minutes (30 seconds on, 30 seconds off cycle) at $4{ }^{\circ} \mathrm{C}$.

440 Immunoprecipitation was performed overnight at $4^{\circ} \mathrm{C}$ using $2 \mu$ of the appropriate

441 antibody and $25 \mu \mathrm{l}$ of protein G magnetic Dynabeads (Invitrogen). ChIP DNA was

442 eluted, and cross-links reversed at $65^{\circ} \mathrm{C}$ in the presence of $1 \%$ SDS. All samples

443 were then treated with RNaseA and proteinase $\mathrm{K}$ before being purified by

444 phenol:chloroform extraction and ethanol precipitation. Libraries were prepared and

445 sequenced as 50bp single end reads on an Illumina Hi seq2000 platform by the

446 Genomics Core Facility at EMBL (Heidelberg, Germany). All ChIP-seq experiments

447 were carried out in biological duplicates.

q-ChIP-seq

449 Quantitative chromatin immunoprecipitation with deep-sequencing (q-ChIP-seq) was

450 performed similarly to the ChIP-seq method, except: $5 \mathrm{ml}$ of an overnight culture of

451 the S. cerevisiae reference strain BY4741 was grown alongside $C$. albicans in YPAD.

452 These cultures were then diluted into fresh YPAD and grown until the exponential

453 phase $\left(\mathrm{OD}_{600}=0.6-0.8\right) .20 \mathrm{OD}_{600}$ units of $C$. albicans cells were combined with 10

$454 \mathrm{OD}_{600}$ units of $S$. cerevisiae cells, and then fixed with $1 \%$ formaldehyde (Sigma) for

45515 minutes at room temperature. After the cells had been fixed, the q-ChIP-seq

456 sample was processed as a single ChIP-seq sample throughout the experiment until

457 completion of DNA sequencing. All q-ChIP-seq experiments were carried out in

458 biological duplicates. 
RNA-seq

460 RNA was extracted from exponential cultures $\left(O D_{600}=0.6-0.8\right)$ using a yeast RNA

extraction kit (E.Z.N.A. Isolation Kit RNA Yeast; Omega Bio-Tek) following the manufacturer's instructions. RNA quality was checked by electrophoresis under denaturing conditions in 1\% agarose, 1x HEPES, $6 \%$ formaldehyde (Sigma). RNA concentration was measured using a NanoDrop ND-1000 spectrophotometer.

Strand-specific cDNA Illumina barcoded libraries were generated from $1 \mu \mathrm{g}$ of total

RNA and sequenced as 50bp single end reads using an Illumina Hi seq2000 seq experiments were carried out in biological duplicates.

\section{Analysis of high-throughput sequencing}

All datasets generated and analysed during the current study are available in the

BioProject NCBI repository (https://www.ncbi.nlm.nih.gov/bioproject) under the

472 BioProject ID (PRJNA503946).

\section{ChIP-seq Analysis:}

474 Illumina reads were mapped using Bowtie2 [63] to a custom haploid version of assembly 22 of the $C$. albicans genome (Table S2). Reads that mapped to repeated sequences were randomly assigned to copies of that repeat, allowing for an estimation of enrichment at the repetitive elements of the genome. Peak calling was performed using MACS2 [64] on the default settings, except that no model was used with all reads extended to $250 \mathrm{bp}$. MACS2 was run separately on both biological replicates for each ChIP-seq sample. For each sample analysed with MACS2, the IP sample was the "treatment," and the input sample was the "control." We defined peaks as reproducible if they were called in both data sets. Read counts within peak intervals were generated using featureCounts [65]. For each interval, biological 
484 duplicate counts were compared between each histone modification and unmodified

485 histone H4 samples using DESeq2, with an adjusted p-value threshold of $<0.05$

486 being used to identify significant differences. Replicates were compared by

487 generating a raw alignment coverage track and performing a Pearson correlation

488 between them using the multiBamSummary and plotCorrelation tools as part of the

489 deepTools2 package (Fig S9) [66]. Genome coverage tracks were made using the

490 pileup function of MACS2 [64] and tracks from biological replicates were averaged

491 after the replicates were deemed to be sufficiently correlative $(r>0.9)$. For each

492 coverage track, reads per million (RPM) were calculated. The histone modification

493 coverage tracks were normalised to unmodified histone H4, and the RNAPII track

494 was normalised to the respective input sample. All coverage tracks were visualised

495 using IGV [67]. Metaplots and heatmaps were made using computeMatrix, plotProfile

496 and plotHeatmap tools as part of the deepTools2 package [66].

q-ChIP-seq Analysis:

498 To isolate the reads that uniquely aligned to the $C$. albicans genome, the full datasets

were first aligned to the $S$. cerevisiae genome (sacCer3). The unaligned reads were

output as separate fastq files, and then these reads were aligned to a custom

haploid version of assembly 22 of the $C$. albicans genome (Table S2). The same

strategy was used to isolate reads that uniquely aligned to $S$. cerevisiae (Table S2).

503 All alignments were performed using Bowtie2 [63]. The unique $S$. cerevisiae reads

were then used to calculate the normalisation factor (normalisation factor $=1 \mathrm{l}$

[unique reference reads $/ 1,000,000]$ ), according to Orlando et al. [48]. Reads that 
509 MACS2 was run separately on both biological replicates for each ChIP-seq sample.

510 For each sample analysed with MACS2, the IP sample was the "treatment," and the

511 input sample was the "control." Peaks called in both replicate datasets for mutant

512 and WT samples were combined into one peak set for each histone modification.

513 Read counts within these peak intervals were generated using featureCounts (Liao

514 et al. 2014), which were then scaled by the normalisation factor to obtain the

515 reference reads per million (RRPM). For each interval, RRPM values were compared

516 between the mutant and WT samples using a two-sample t-test, with a p-value

517 threshold of $<0.05$ being used to identify significant differences. Replicates were

518 compared by generating a raw alignment coverage track and performing a Pearson

519 correlation between them using the multiBamSummary and plotCorrelation tools as

520 part of the deepTools2 package (Fig S9) [66]. Genome coverage tracks were made

521 using the pileup function of MACS2 [64] and for each track, RRPM values were

522 calculated using the normalisation factor. Coverage tracks from biological replicates

523 were averaged after the replicates were deemed to be sufficiently correlative $(r>$

524 0.9), and the mutant strain coverage tracks were normalised to the WT coverage. All

525 tracks were visualised using IGV [67]. Metaplots and heatmaps were made using

526 computeMatrix, plotProfile and plotHeatmap tools as part of the deepTools2 package

$527 \quad[66]$.

528 RNA-seq Analysis:

529 Reads were aligned to a custom haploid version of assembly 22 of the C. albicans

530 genome using HISAT2 (Table SX) [68], and per-gene transcript quantification was

531 performed using featureCounts, which discards multi-mapped read fragments;

532 therefore, only uniquely mapped reads were included for the expression analysis

533 [65]. Differential expression testing was performed using DESeq2, with an adjusted 
$534 p$-value threshold of $<0.05$ being used to determine statistical significance.

535 Replicates were compared by generating a raw alignment coverage track and

536 performing a Pearson correlation between them using the multiBamSummary and

537 plotCorrelation tools as part of the deepTools2 package (Fig S10) [66]. Scatterplots

538 and correlation analyses were performed in R using Pearson correlation.

540 DECLARATION

541 Ethics approval and consent to participate: 'Not applicable'; Consent for publication:

542 'Not applicable'; Availability of data and material: The datasets generated and

543 analysed during the current study are available in the BioProject NCBI repository

544 (https://www.ncbi.nlm.nih.gov/bioproject) under the BioProject ID (PRJNA503946);

545 Competing interests: 'Not applicable'; Funding: This work was supported by MRC

546 (MR/M019713/1 to A.B., R.J.P.) and an ERC Grant (340087, RAPLODAPT to J.B.)

547 Authors' contributions R.J.P conducted the ChIP seq, the RNA-seq and the

548 bioinformatics analyses. E.W performed RNAseq experiments of sir2 $\Delta / \Delta$ strain. A.B

549 and J.B conceived the project, designed the experiments and wrote the manuscript.

550 Acknowledgements: We thank members of the Kent Fungal Group, Jan Soetaert and

551 Alison Pidoux for discussion and critical reading of the manuscript. We thank the

552 Gene Core Facility at EMBL (Heidelberg-Germany) for Illumina Sequencing.

\section{REFERENCES}

554 1. Allshire RC, Madhani HD. Ten principles of heterochromatin formation and

555 function. Nat. Rev.;19:229-44.

556 2. Strahl BD, Allis CD. The language of covalent histone modifications. Nature.

$557 \quad 2000 ; 403: 41-5$.

558 3. Allis CD, Jenuwein T. The molecular hallmarks of epigenetic control. Nat. Rev. 
559 Genet. 2016;17:487-500.

560 4. Van HT, Santos MA. Histone Modifications and the DNA Double-Strand Break

561 Response. Cell Cycle Taylor \& Francis; 2018;0:15384101.2018.1542899.

562 5. Ernst J, Kheradpour P, Mikkelsen TS, Shoresh N, Ward LD, Epstein CB, et al.

563 Mapping and analysis of chromatin state dynamics in nine human cell types. Nature.

$564 \quad 2011 ; 473: 43-9$.

565 6. Guttman M, Amit I, Garber M, French C, Lin MF, Feldser D, et al. Chromatin

566 signature reveals over a thousand highly conserved large non-coding RNAs in

567 mammals. Nature 2009;458:223-7.

568 7. Janssen A, Colmenares SU, Karpen GH. Heterochromatin: Guardian of the

569 Genome. Annu. Rev. Cell Dev. Biol. 2018;34:annurev-cellbio-100617-062653.

570 8. Howe FS, Fischl H, Murray SC, Mellor J. Is H3K4me3 instructive for transcription

571 activation? BioEssays. 2017;39:1-12.

572 9. Wang Z, Zang C, Rosenfeld JA, Schones DE, Barski A, Cuddapah S, et al.

573 Combinatorial patterns of histone acetylations and methylations in the human

574 genome. Nat. Genet. 2008;40:897-903.

575 10. Heintzman ND, Stuart RK, Hon G, Fu Y, Ching CW, Hawkins RD, et al. Distinct

576 and predictive chromatin signatures of transcriptional promoters and enhancers in

577 the human genome. Nat. Genet. 2007;39:311-8.

578 11. Padeken J, Zeller P, Gasser SM. Repeat DNA in genome organization and

579 stability. Curr. Opin. Genet. Dev.; 2015;31:12-9.

580 12. Nair N, Shoaib M, Sørensen CS. Chromatin dynamics in genome stability: Roles

581 in suppressing endogenous DNA damage and facilitating DNA repair. Int. J. Mol. Sci.

$582 \quad 2017 ; 18: 1-21$.

583 13. Shaver S, Casas-Mollano JA, Cerny RL, Cerutti H. Origin of the polycomb 
584 repressive complex 2 and gene silencing by an $E(z)$ homolog in the unicellular alga

585 Chlamydomonas. Epigenetics. 2010;5:301-12.

586 14. Szilard RK, Jacques P-E, Laramée L, Cheng B, Galicia S, Bataille AR, et al.

587 Systematic identification of fragile sites via genome-wide location analysis of

588 gamma-H2AX. Nat. Struct. Mol. Biol. 2010;17:299-305.

589 15. Kitada T, Schleker T, Sperling AS, Xie W, Gasser SM, Grunstein M. YH2A is a

590 component of yeast heterochromatin required for telomere elongation. Cell Cycle.

$591 \quad 2011 ; 10: 293-300$.

592 16. Rozenzhak S, Mejía-Ramírez E, Williams JS, Schaffer L, Hammond J a, Head

$593 \mathrm{SR}$, et al. Rad3 decorates critical chromosomal domains with gammaH2A to protect

594 genome integrity during S-Phase in fission yeast. PLoS Genet. 2010 ;6:e1001032.

595 17. Sasaki T, Lynch KL, Mueller C V., Friedman S, Freitag M. et al Heterochromatin

596 controls yH2A localization in Neurospora crassa. Eukaryot. Cell. 2014;13:990-1000.

597 18. Meier A, Fiegler H, Muñoz P, Ellis P, Rigler D, Langford C, et al. Spreading of

598 mammalian DNA-damage response factors studied by ChIP-chip at damaged

599 telomeres. EMBO J.; 2007;26:2707-18.

600 19. Iacovoni JS, Caron P, Lassadi I, Nicolas E, Massip L, Trouche D, et al. High-

601 resolution profiling of gammaH2AX around DNA double strand breaks in the

602 mammalian genome. EMBO J.; 2010;29:1446-57.

603 20. Clouaire T, Rocher V, Lashgari A, Arnould C, Aguirrebengoa M, Biernacka A, et

604 al. Comprehensive Mapping of Histone Modifications at DNA Double-Strand Breaks

605 Deciphers Repair Pathway Chromatin Signatures. Mol. Cell . 2018;1-13.

606 21. Wang J, Jia ST, Jia S. New Insights into the Regulation of Heterochromatin.

607 Trends Genet. 2016;32:284-94.

608 22. De Las Peñas A, Juárez-Cepeda J, López-Fuentes E, Briones-Martín-del-Campo 
609 M, Gutiérrez-Escobedo G, Castaño I. Local and regional chromatin silencing in

610 Candida glabrata $\square$ : consequences for adhesion and the response to stressFEMS

611 Yeast Res. 2015;15:fov056.

612 23. Brown GD, Denning DW, Gow NAR, Levitz SM, Netea MG, White TC. Hidden

613 Killers: Human Fungal Infections. Sci. Transl. Med. 2012;4:165rv13-165rv13.

614 24. Selmecki A, Forche A, Berman J. Genomic plasticity of the human fungal

615 pathogen Candida albicans. Eukaryot. Cell. 2010;9:991-1008.

616 25. Muzzey D, Schwartz K, Weissman JS, Sherlock G. Assembly of a phased diploid

617 Candida albicans genome facilitates allele-specific measurements and provides a

618 simple model for repeat and indel structure. Genome Biol. 2013;14:R97.

619 26. Bruno VM, Wang Z, Marjani SL, Euskirchen GM, Martin J, Sherlock G, et al.

620 Comprehensive annotation of the transcriptome of the human fungal pathogen

621 Candida albicans using RNA-seq. Genome Res. 2010;20:1451-8.

622 27. Sellam A, Hogues H, Askew C, Tebbji F, van Het Hoog M, Lavoie H, et al.

623 Experimental annotation of the human pathogen Candida albicans coding and

624 noncoding transcribed regions using high-resolution tiling arrays. Genome Biol.

$625 \quad 2010 ; 11: R 71$.

626 28. Tuch BB, Mitrovich QM, Homann OR, Hernday AD, Monighetti CK, De La Vega

627 FM, et al. The transcriptomes of two heritable cell types illuminate the circuit

628 governing their differentiation. Copenhaver GP, editor. PLoS Genet.

$629 \quad 2010 ; 6: \mathrm{e} 1001070$.

630 29. van het Hoog M, Rast TJ, Martchenko M, Grindle S, Dignard D, Hogues H, et al.

631 Assembly of the Candida albicans genome into sixteen supercontigs aligned on the

632 eight chromosomes. Genome Biol. 2007;8:R52.

633 30. McEachern MJ, Hicks JB. Unusually large telomeric repeats in the yeast Candida 
634 albicans. Mol. Cell. Biol. 1993;13:551-60. A

635 31. Jones T, Federspiel NA, Chibana H, Dungan J, Kalman S, Magee BB, et al. The

636 diploid genome sequence of Candida albicans. Proc. Natl. Acad. Sci. U. S. A.

$637 \quad 2004 ; 101: 7329-34$.

638 32. Chibana H, Magee PT. The enigma of the major repeat sequence of Candida 639 albicans. Future Microbiol. 2009;4:171-9.

640 33. Uhl MA, Biery M, Craig N, Johnson AD. Haploinsufficiency-based large-scale 641 forward genetic analysis of filamentous growth in the diploid human fungal pathogen

642 C.albicans. EMBO J. 2003;22:2668-78.

643 34. Goodwin TJD. Multiple LTR-Retrotransposon Families in the Asexual Yeast

644 Candida albicans. Genome Res. $2000 ; 10: 174-91$.

645 35. Zhang L, Yan L, Jiang J, Wang Y, Jiang Y, Yan T, et al. The structure and

646 retrotransposition mechanism of LTR-retrotransposons in the asexual yeast Candida 647 albicans. Virulence. 2014;5:1-10.

648 36. Goodwin TJD, Ormandy JE, Poulter RTM. L1-like non-LTR retrotransposons in 649 the yeast Candida albicans. Curr. Genet. 2001;39:83-91.

650 37. Hirakawa MP, Martinez DA, Sakthikumar S, Anderson MZ, Berlin A, Gujja S, et

651 al. Genetic and phenotypic intra-species variation in Candida albicans. Genome Res.

$652 \quad 2015 ; 25: 413-25$.

653 38. Ene I V., Farrer RA, Hirakawa MP, Agwamba K, Cuomo CA, Bennett RJ. Global

654 analysis of mutations driving microevolution of a heterozygous diploid fungal

655 pathogen. Proc. Natl. Acad. Sci. 2018;115:201806002.

656 39. Freire-Benéitez V, Price RJ, Buscaino A. The Chromatin of Candida albicans

657 Pericentromeres Bears Features of Both Euchromatin and Heterochromatin. Front.

658 Microbiol. 2016;7:759. 
659 40. Peterson M, Price RJ, Gourlay S, May A, Tullet J, Buscaino A. The fungal-

660 specific Hda2 and Hda3 proteins regulate morphological switches in the human

661 fungal pathogen Candida albicans. bioRxiv. Cold Spring Harbor Laboratory;

$662 \quad 2018 ; 340364$.

663 41. Anderson MZ, Bennett RJ. Budding off: Bringing functional genomics to Candida 664 albicans. Brief. Funct. Genomics. 2016;15:85-94.

665 42. Kim J, Lee J-E, Lee J-S. Histone deacetylase-mediated morphological transition 666 in Candida albicans. J. Microbiol. 2015;53:805-11.

667 43. Thakur J, Sanyal K. Efficient neocentromere formation is suppressed by gene 668 conversion to maintain centromere function. Genome Research. 2013;638-52.

669 44. Shroff R, Arbel-Eden A, Pilch D, Ira G, Bonner WM, Petrini JH, et al. Distribution 670 and Dynamics of Chromatin Modification Induced by a Defined DNA Double-Strand 671 Break. Curr. Biol; 2004;14:1703-11.

672 45. Ellahi A, Thurtle DM, Rine J. The Chromatin and Transcriptional Landscape of 673 Native Saccharomyces cerevisiae Telomeres and Subtelomeric Domains. Genetics. $674 \quad 2015 ; 200: 505-21$.

675 46. Freire-Benéitez V, Price RJ, Tarrant D, Berman J, Buscaino A. Candida albicans 676 repetitive elements display epigenetic diversity and plasticity. Sci. Rep.

$677 \quad 2016 ; 6: 22989$.

678 47. Hu B, Petela N, Kurze A, Chan KL, Chapard C, Nasmyth K. Biological

679 chromodynamics: A general method for measuring protein occupancy across the 680 genome by calibrating ChIP-seq. Nucleic Acids Res. 2015;43.

681 48. Orlando DA, Chen MW, Brown VE, Solanki S, Choi YJ, Olson ER, et al.

682 Quantitative ChIP-Seq normalization reveals global modulation of the epigenome. 683 Cell Rep; 2014;9:1163-70. 
684 49. Helman E, Lawrence MS, Stewart C, Sougnez C, Getz G, Meyerson M, et al.

685 Quantifying ChIP-seq data $\square$ : a spiking method providing an internal reference for A

686 cloud-compatible bioinformatics pipeline for ultrarapid pathogen identification.

687 Genome Res. 2014;24:1157-68.

688 50. Schwartz K, Sherlock G. High-Throughput Yeast Strain Sequencing. Cold Spring 689 Harb. Protoc. 2016:pdb.top077651.

690 51. Krogan NJ, Dover J, Khorrami S, Greenblatt JF, Schneider J, Johnston M, et al.

691 COMPASS, a histone H3 (Lysine 4) methyltransferase required for telomeric

silencing of gene expression. J. Biol. Chem. 2002;277:10753-5.

52. Bryk M, Briggs SD, Strahl BD, Curcio MJ, Allis CD, Winston F. Evidence that

Set1, a factor required for methylation of histone $\mathrm{H} 3$, regulates rDNA silencing in $\mathrm{S}$.

cerevisiae by a Sir2-independent mechanism. Curr. Biol.. 2002;12:165-70.

53. Margaritis T, Oreal V, Brabers N, Maestroni L, Vitaliano-Prunier A, Benschop JJ,

et al. Two Distinct Repressive Mechanisms for Histone 3 Lysine 4 Methylation

through Promoting 3'-End Antisense Transcription. PLoS Genet. 2012;8.

54. Ramakrishnan S, Pokhrel S, Palani S, Pflueger C, Parnell TJ, Cairns BR, et al.

Counteracting H3K4 methylation modulators Set1 and Jhd2 co-regulate chromatin

dynamics and gene transcription. Nat. Commun. 2016;7:11949.

55. Weiner A, Hsieh THS, Appleboim A, Chen H V., Rahat A, Amit I, et al. High-

resolution chromatin dynamics during a yeast stress response. Mol. Cell.

$2015 ; 58: 371-86$.

56. Lorenz DR, Meyer LF, Grady PJR, Meyer MM, Cam HP. Heterochromatin 
albicans SET1 encodes a histone 3 lysine 4 methyltransferase that contributes to the pathogenesis of invasive candidiasis. Mol. Microbiol. 2006;60:697-709.

58. Mellone BG, Ball L, Suka N, Grunstein MR, Partridge JF, Allshire RC.

Centromere Silencing and Function in Fission Yeast Is Governed by the Amino

Terminus of Histone H3. Curr. Biol. Cell Press; 2003;13:1748-57.

59. Hirakawa MP, Martinez D a, Sakthikumar S, Anderson MZ, Berlin A, Gujja S, et al. Genetic and phenotypic intra-species variation in Candida albicans. 2015;1-13.

60. Forche A, Abbey D, Pisithkul T, Weinzierl MA, Ringstrom T, Bruck D, et al.

Stress alters rates and types of loss of heterozygosity in Candida albicans. MBio. $2011 ; 2$

61. Freire-Benéitez V, Gourlay S, Berman J, Buscaino A. Sir2 regulates stability of repetitive domains differentially in the human fungal pathogen Candida albicans. Nucleic Acids Res. 2016;44.

62. Santos-Pereira JM, Aguilera A. R loops: new modulators of genome dynamics and function. Nat. Rev. Genet. 2015;16:583-97.

63. Langmead B, Salzberg SL. Fast gapped-read alignment with Bowtie 2. Nat. Methods [Internet]. 2012;9:357-9.

64. Feng J, Liu T, Qin B, Zhang Y, Liu XS. Identifying ChIP-seq enrichment using MACS. Nat. Protoc. 2012;7:1728-40.

65. Liao Y, Smyth GK, Shi W. featureCounts: an efficient general purpose program for assigning sequence reads to genomic features. Bioinformatics. 2014;30:923-30.

66. Ramírez F, Ryan DP, Grüning B, Bhardwaj V, Kilpert F, Richter AS, et al. deepTools2: a next generation web server for deep-sequencing data analysis. Nucleic Acids Res. 2016;44:W160-5.

67. Thorvaldsdóttir H, Robinson JT, Mesirov JP. Integrative Genomics Viewer (IGV): 
734 high-performance genomics data visualization and exploration. Brief. Bioinform.

$735 \quad 2013 ; 14: 178-92$.

736 68. Kim D, Langmead B, Salzberg SL. HISAT: a fast spliced aligner with low memory

737 requirements. Nat. Methods. 2015;12:357-60.

\section{ADDITIONAL FILES}

739 Additional file 1-10: Fig S1 to S10. pdf

740 Additional file 11: Table S1: Strains used in this study

741 Additional file 12: Table S2.xsl ; Sequencing and coverage information

742 Additional file 13: Dataset S1.xsl ; Datasets generated in this study

\section{FIGURE LEGENDS}

744 Figure 1 Histones and RNA Polymerase II occupancy (A) Correlation between H3 745 and $\mathrm{H} 4$ occupancy (log10 counts at $1 \mathrm{~kb}$ bins) across the $C$. albicans genome. (B) 746 Correlation between RNAPII occupancy (log10 counts) and transcriptional levels 747 (RNA-seq; log10 counts) at protein-coding genes. (C) Histone H3 is depleted at centromeric regions. Fold enrichment (log2) of histone $\mathrm{H} 3$ relative to unmodified $\mathrm{H} 4$ across CEN1 (Chr1) and CEN5 (Chr5) centromeric and pericentromeric regions in $C$.

750 albicans. The Cse4 ${ }^{\text {CENP-A }}$ enrichment profile [43] is shown as comparison. The blue 751 bar indicates statistically significant depleted regions for histone H3.

752 Figure 2 C. albicans chromatin modifications mirror their transcriptional state (A) 753 Chromatin signature of $C$. albicans genes $(n=6408)$. Average profiles and heatmaps 754 of histone modification signatures around the Transcriptional Start Sites (TSS) of 755 genes. The relative fold enrichment (log2) for each histone modification normalised 756 to unmodified histone $\mathrm{H} 4$, or aligned reads of immunoprecipitated (IP) sample 757 normalised to aligned reads of Input sample (for RNAPII ChIP-seq) is displayed 758 within a region spanning $\pm 0.5 \square \mathrm{kb}$ around TSS. The gradient blue-to-red colour 
759 indicates high-to-low enrichment in the corresponding region. Min: - 1.5 log2. Max: +

$7601.5 \log 2 .(B)$ Average profiles of histone modifications and RNAPII occupancy across

761 gene sets of different expression level ( $\mathrm{no}[\mathrm{n}=416]$, low $[\mathrm{n}=1369]$, medium $[\mathrm{n}=$

762 3570] and high [ $\mathrm{n}=983$ ] expression). For each histone modification, the fold

763 enrichment (log2) relative to unmodified $\mathrm{H} 4$ is shown. For RNAPII the IP/I

764 enrichment $(\log 2)$ is shown.

765 Figure 3 Identification of $C$. albicans $\gamma$-sites (A) Locations and frequencies of $\gamma$-sites

766 throughout the $C$. albicans genome. (B) $\gamma$-sites map to longer genes. Histogram

767 showing the gene lengths of $\gamma$-sites (red) compared to the genome average (grey)

768 (C) Chromatin signature of $\gamma$-sites throughout the $C$. albicans genome. Average

769 profiles and heatmaps of histone modification signatures at $\gamma$-sites. The relative fold

770 enrichment (log2) for each histone modification normalised to unmodified histone $\mathrm{H} 4$

771 is displayed within a region spanning $\pm 2 \square \mathrm{kb}$ around the $\gamma \mathrm{H} 2 \mathrm{~A}$ peak summits. The

772 gradient blue-to-red colour indicates high-to-low enrichment in the corresponding

773 region. Min: - $1.5 \log 2$. Max: + $1.5 \log 2$.

774 Figure 4 Chromatin signature of C. albicans repetitive elements (A) Top: Fold 775 enrichment $(\log 2)$ of $\mathrm{H}_{3} \mathrm{~K} 4 \mathrm{me}^{3}, \mathrm{H} 3 \mathrm{~K} 9 \mathrm{Ac}, \mathrm{H} 4 \mathrm{~K} 16 \mathrm{Ac}, \gamma \mathrm{H} 2 \mathrm{~A}$ and $\mathrm{H} 3$ relative to 776 unmodified $\mathrm{H} 4$ across the $20 \mathrm{~kb}$ right terminal region of chromosome 6 (Chr6). 777 Middle: Diagram of coding genes found at these regions, according to assembly 22. 778 Bottom: Diagram depicting statistically significant enriched (red) or depleted (blue) 779 domains for each histone modification. (B) Top: Fold enrichment (log2) of H3K4me3, $780 \mathrm{H} 3 \mathrm{~K} 9 \mathrm{Ac}, \mathrm{H} 4 \mathrm{~K} 16 \mathrm{Ac}, \gamma \mathrm{H} 2 \mathrm{~A}$ and $\mathrm{H} 3$ relative to unmodified $\mathrm{H} 4$ at the rDNA locus and 781 flanking regions (ChrR). Middle: Diagram of coding genes (white) and ncRNA (grey) 782 found at this region, according to assembly 22. Bottom: Diagram depicting 783 statistically significant enriched (red) or depleted (blue) domains for each histone 
784 modification (C) Average profiles of histone modifications at MRS repeats, and 785 upstream and downstream sequences. The grey arrow indicates the location of the 786 FGR gene. For each histone modification, the fold enrichment $(\log 2)$ relative to 787 unmodified H4 is shown. (D) Left: Diagrams of the structure of the C. albicans LTR 788 and non-LTR retrotransposons. Right: Chromatin signature of LTR and non-LTR 789 retrotransposons. Average profiles and heatmaps of histone modification signatures 790 across each sequence. The relative fold enrichment (log2) for each histone 791 modification normalised to unmodified histone $\mathrm{H} 4$, or aligned reads of 792 immunoprecipitated (IP) sample normalised to aligned reads of Input sample (for 793 RNAPII ChIP-seq) is displayed. The gradient blue-to-red colour indicates high-to-low 794 enrichment in the corresponding region. Min: - $1.5 \log 2$. Max: + $1.5 \log 2$.

795 Figure 5 The HDAC Sir2 controls the chromatin state of subtelomeres and the rDNA 796 locus (A) Schematic of the quantitative ChIP-seq experimental and analytical 797 workflow. (B) Top: Fold enrichment (log2) of H3K9Ac and H4K16Ac relative to 798 unmodified H4 in WT cells, and relative to WT in sir2 $\Delta \Delta$ cells, across the rDNA loci 799 of chromosome $\mathrm{R}(\mathrm{ChrR})$. Middle: Diagram of transcripts found at this region, 800 according to assembly 22. Bottom: Heatmap depicting changes in gene and ncRNA expression across the rDNA region in sir2 $\Delta \Delta$ cells relative to WT. The gradient yellow-to-blue colour indicates high-to-low expression. Min: - 2 log2. Max: $+2 \log 2$. (C) Left: Fold enrichment (log2) of H3K9Ac and H4K16Ac relative to unmodified H4 804 in WT cells, and relative to WT in sir2 $\Delta / \Delta$ cells, across the $20 \mathrm{~kb}$ left and right 805 terminal regions of chromosome 3 (Chr3). Diagrams of coding genes (TLO: grey) 806 found at these regions, according to assembly 22, are below. Right: Heatmap 807 depicting changes in gene and ncRNA expression in sir2 $\Delta \Delta$ cells relative to WT at 
808 the $10 \mathrm{~kb}$ terminal regions of all C. albicans chromosomes. The gradient yellow-toblue colour indicates high-to-low expression. Min: - 2 log2. Max: +2 log2.

810 Figure 6 Chromatin and gene expression changes of $\operatorname{set} 1 \Delta / \Delta$ strain (A) Heatmap

811 depicting changes in expression of genes and ncRNA associated with statistically 812 significant changes in $\mathrm{H} 3 \mathrm{~K} 4 \mathrm{me}^{3}$ enrichment in set1 $\Delta / \Delta$ cells relative to WT cells. The 813 gradient yellow-to-blue colour indicates high-to-low enrichment/expression. Min: - 4 814 log2. Max: $+4 \log 2$ (B) Top: Fold enrichment $(\log 2)$ of $H 3 K 4 m e^{3}$ relative to 815 unmodified H4 in WT cells, and relative to WT in set1 $\Delta / \Delta$ cells, across the $20 \mathrm{~kb}$ left and right terminal regions of chromosome 3 (Chr3). Diagrams of coding genes (TLO: grey) found at these regions, according to assembly 22, are below. Bottom: Heatmap depicting changes in gene and ncRNA expression in set1 $4 / \Delta$ cells relative to WT at the $10 \mathrm{~kb}$ terminal regions of all $C$. albicans chromosomes. The gradient yellow-toblue colour indicates high-to-low expression. Min: - 2 log2. Max: +2 log2. (C) Left:

821 Fold enrichment (log2) of $\mathrm{H}_{3} \mathrm{~K} 4 \mathrm{me}^{3}$ relative to unmodified $\mathrm{H} 4$ in WT cells, and relative to WT in set1 $\Delta / \Delta$ cells, across the rDNA loci of chromosome $R(C h r R)$. Diagrams of coding genes and ncRNA (grey) found at this region, according to assembly 22, are below. Right: Heatmap depicting changes in gene and ncRNA expression across the rDNA region in set1 $\Delta / \Delta$ cells relative to WT. The gradient yellow-to-blue colour indicates high-to-low expression. Min: - 2 log2. Max: $+2 \log 2$. (D) Left: Profiles of fold enrichment $(\log 2)$ of $\mathrm{H} 3 \mathrm{~K} 4 \mathrm{me}^{3}$ relative to unmodified $\mathrm{H} 4$ in 828 WT cells, and relative to WT in set1 $\Delta / \Delta$ cells averaged across the MRS repeats, and the upstream and downstream sequences. The grey arrow indicates the location of 830 the FGR gene. Right: Heatmap depicting changes in gene and ncRNA expression 831 across all of the MRS regions in set1 $\Delta / \Delta$ cells relative to WT. The gradient yellow-to832 blue colour indicates high-to-low expression. Min: - 2 log2. Max: + 2 log2. 
Price et al

Fig 2

A Chromatin signature of protein-coding genes

B
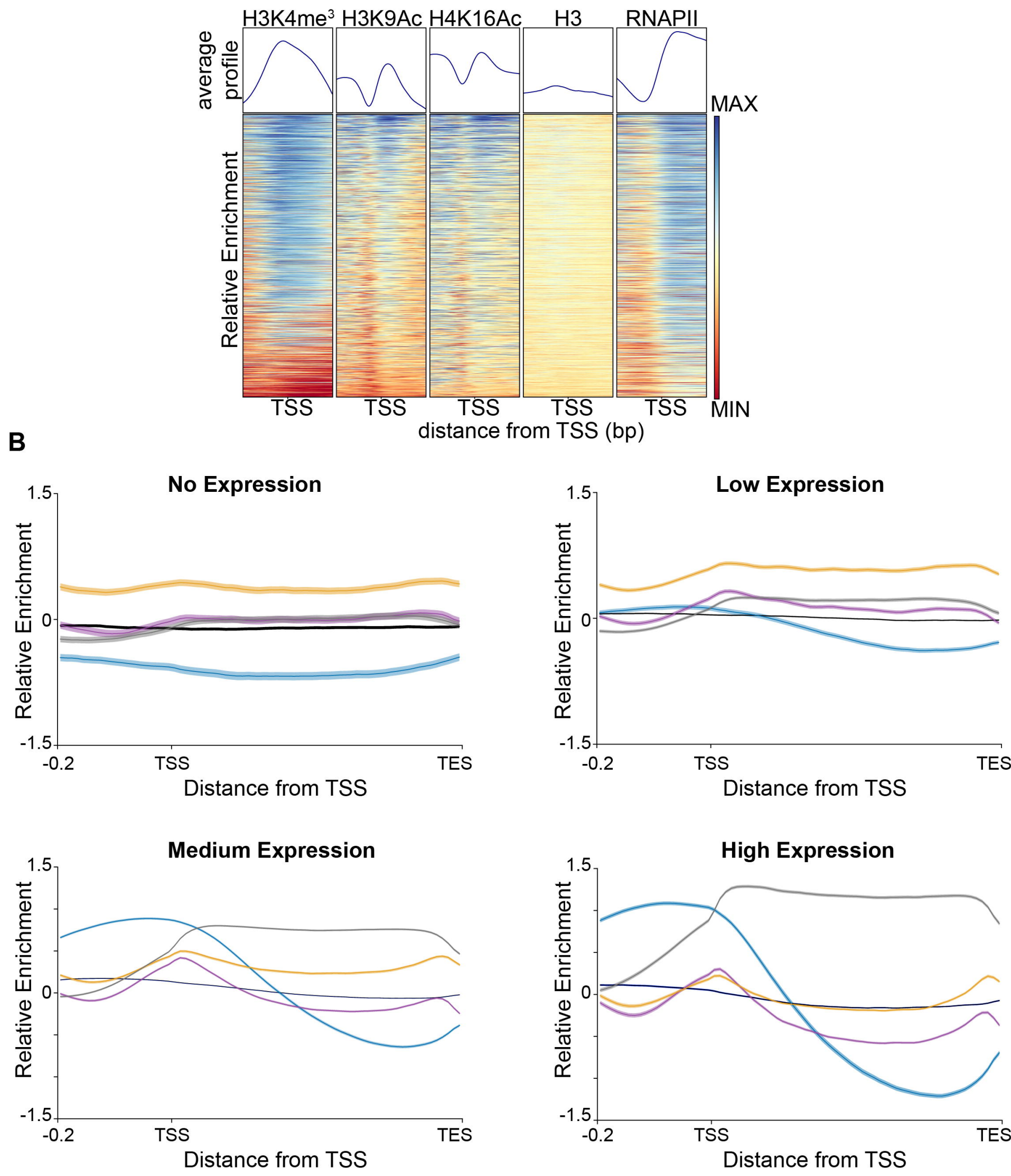


\section{Fig 3}

A

C. albicans $\gamma$-sites

B

Subtelomeres $37.5 \%$

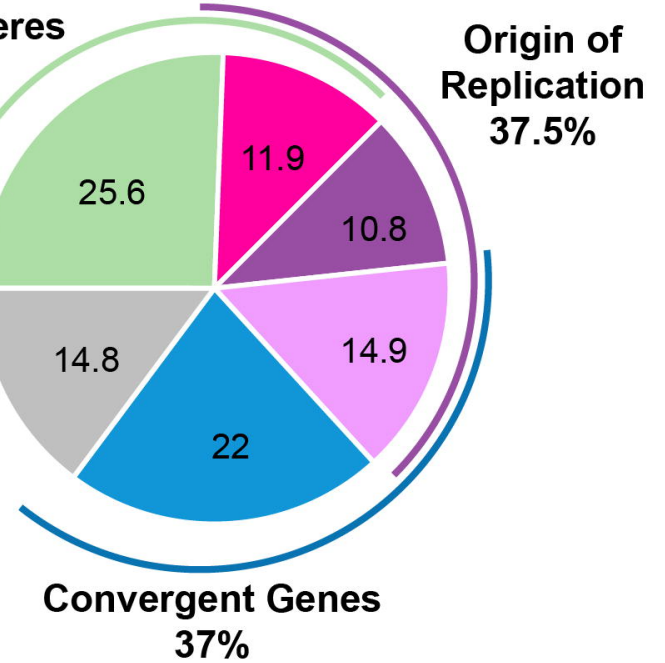

$37 \%$

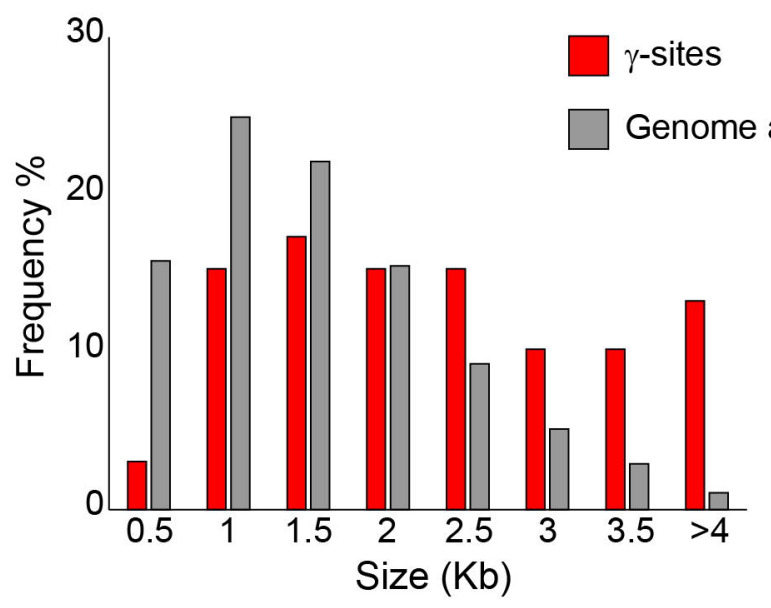

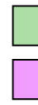

Chromatin signature of $\gamma$-sites

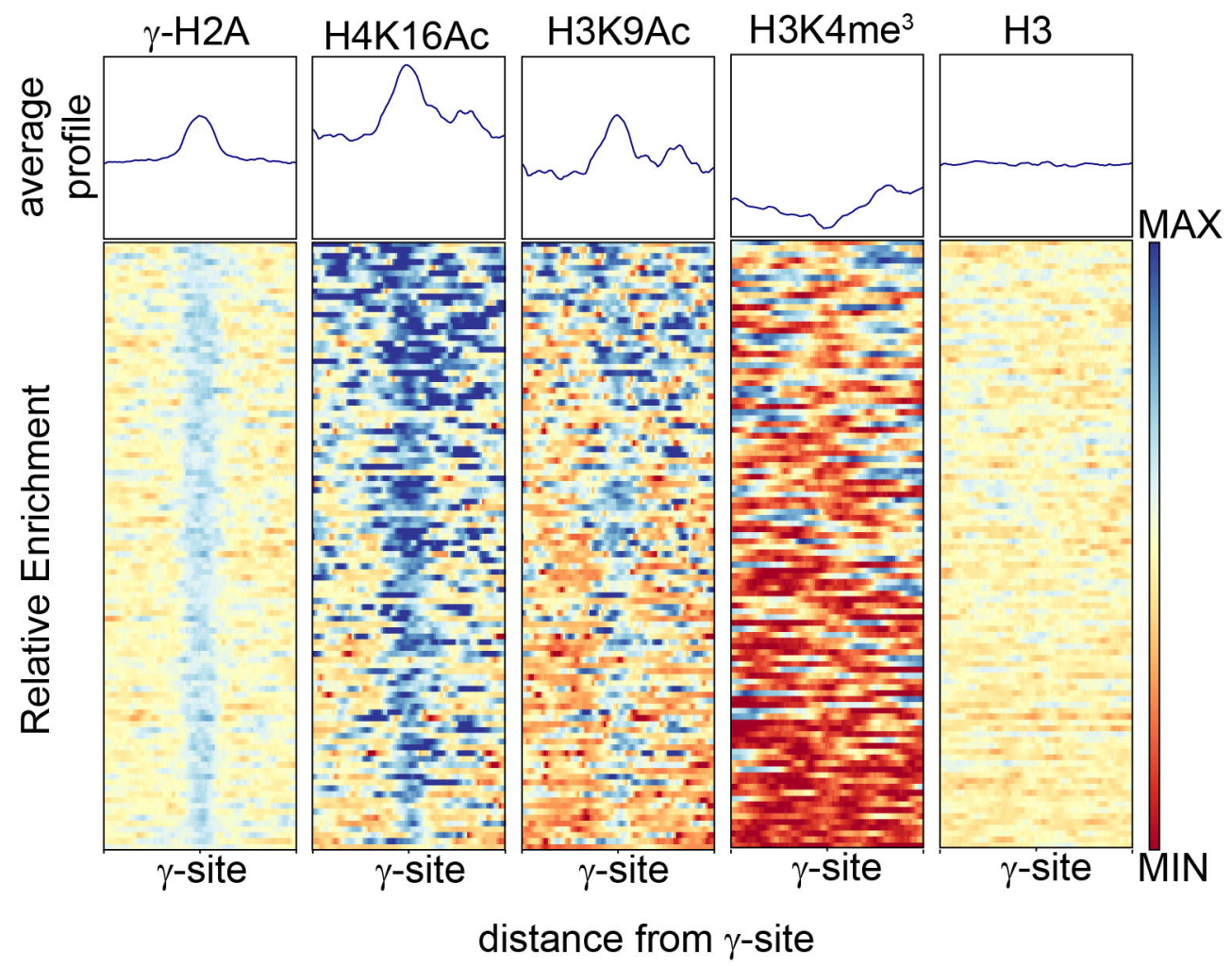


Price et al

Fig 4

A

Subtelomeric regions not certified by peer review) is the authorffunder, who has grantedbionxt a license to display the preprint in perpetuity. It is made available

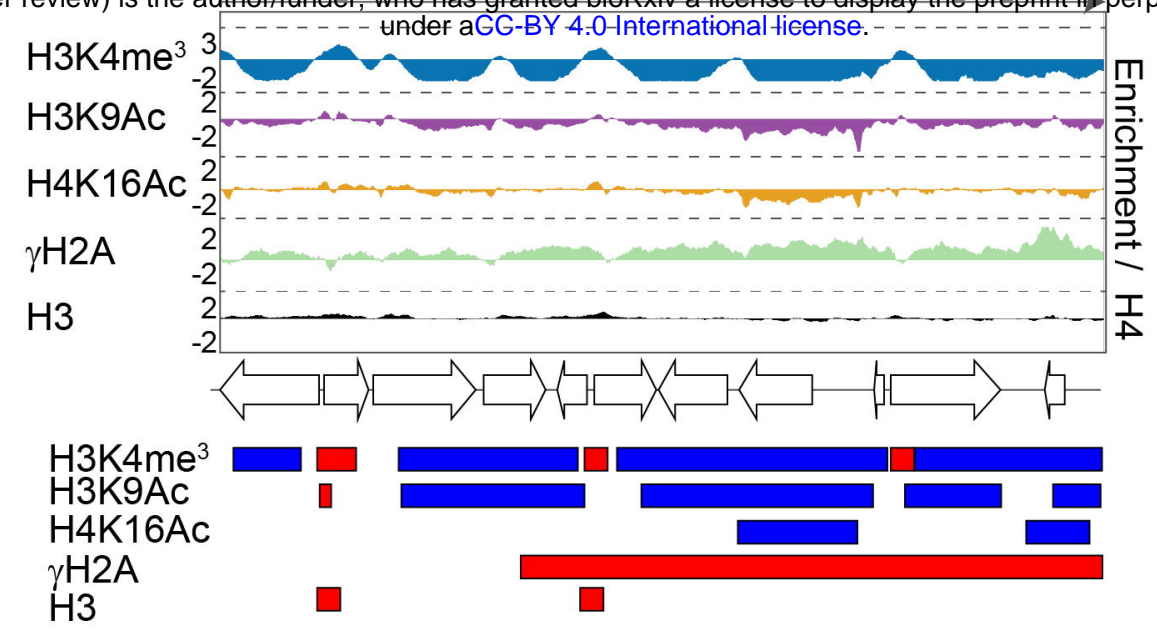

B

rDNA locus ChrR

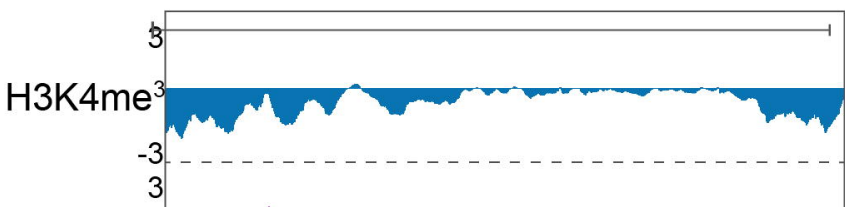

$\mathrm{H} 3 \mathrm{~K} 9 \mathrm{Ac}$

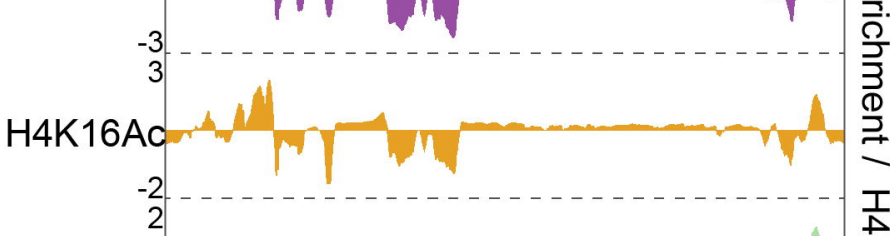

$\gamma \mathrm{H} 2 \mathrm{~A}$

$\mathrm{H} 3$

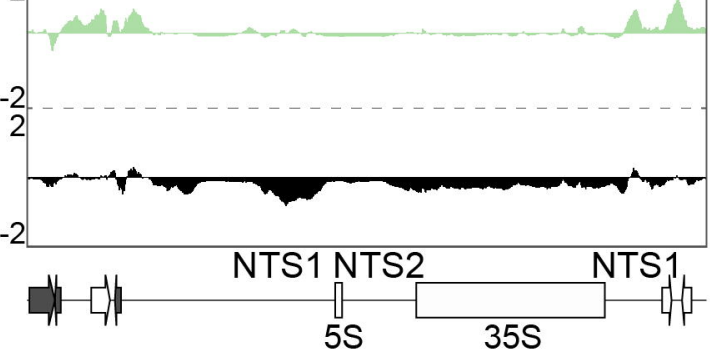

C

\section{MRS}

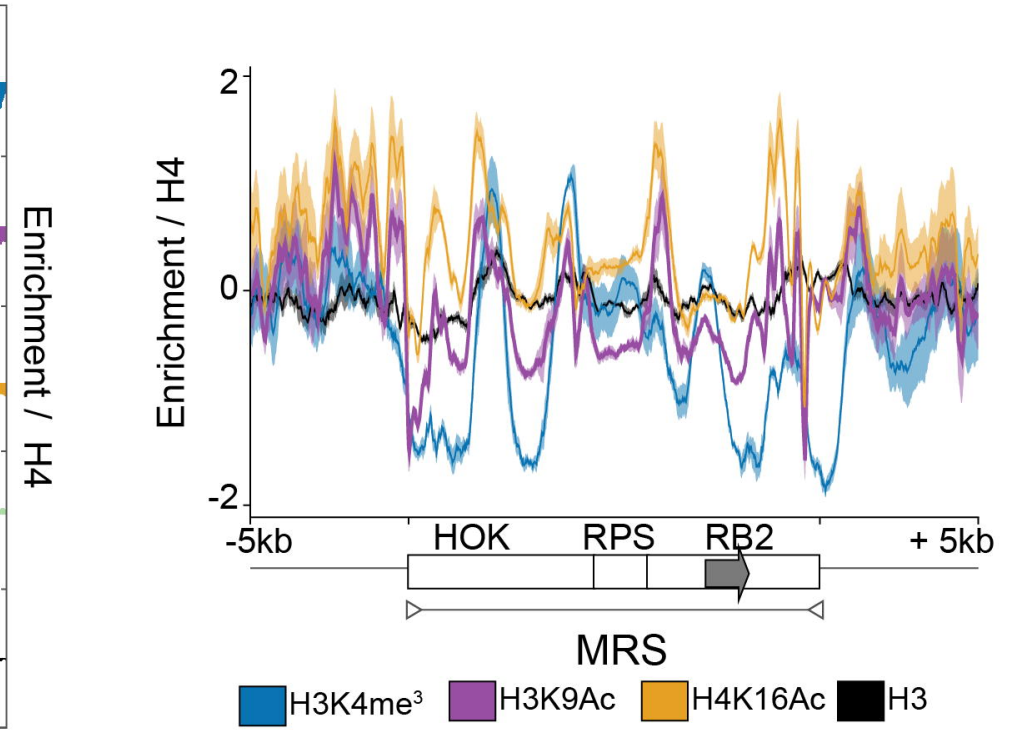

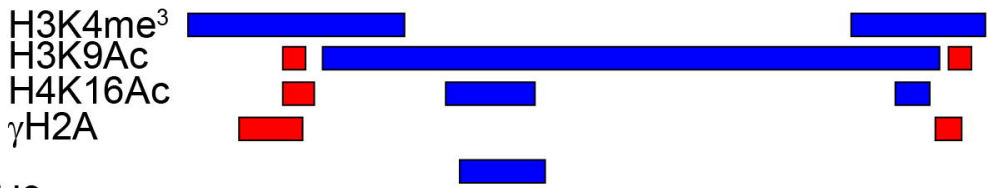

$\mathrm{H} 3$

D

LTR

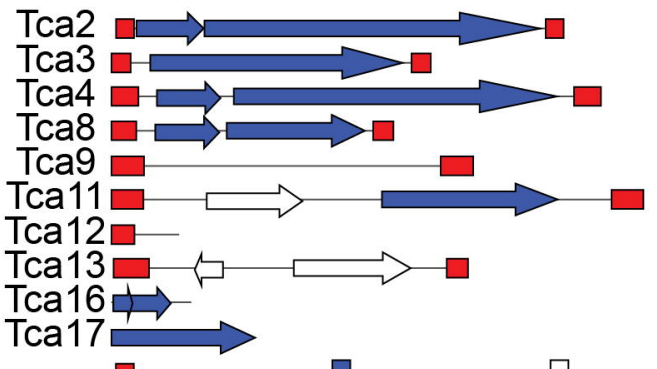

LTR GAG/POL Unknown

\section{non-LTR}

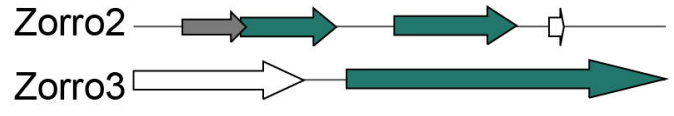

Retroviral Reverse

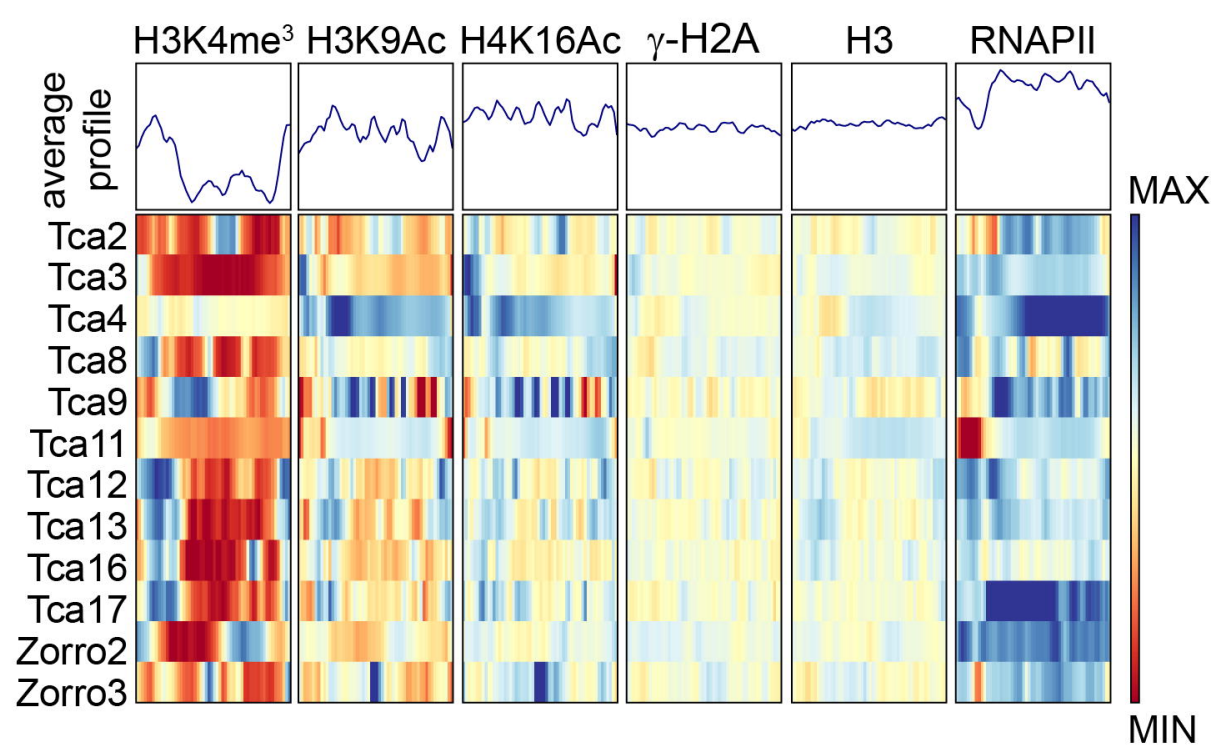


Price et al

Fig 5

A

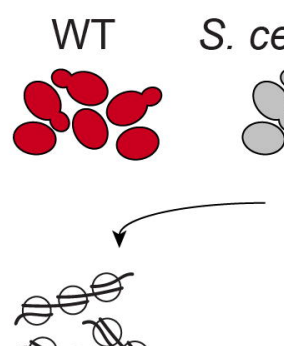

$2: 1$

$Q 2$

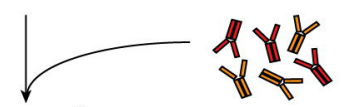

$\frac{f}{2}$

Library Preparation and Illumina Sequencing
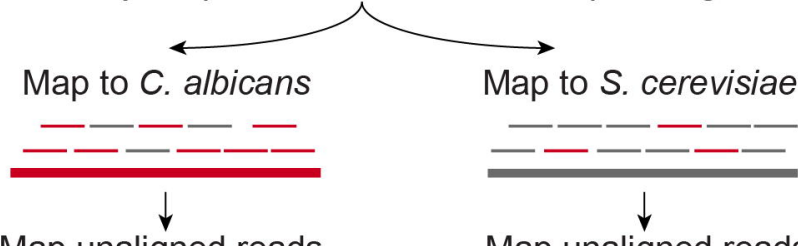

Map unaligned reads

to S. cerevisiae

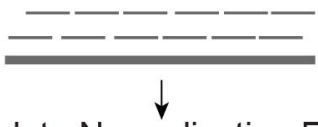

Calculate Normalisation Factor from S. cerevisiae counts

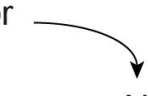

Normalisation
Map unaligned reads to $C$. albicans
B

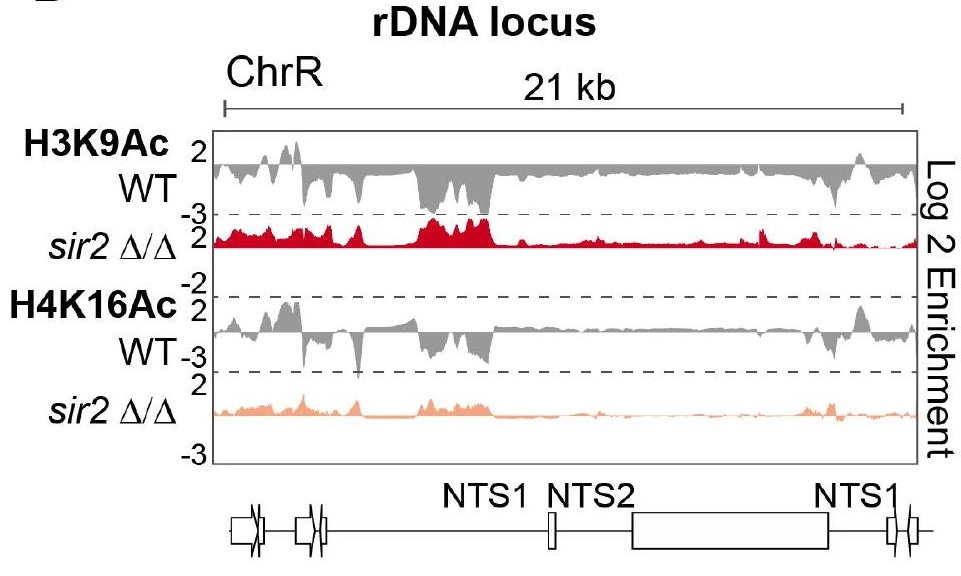

Gene Expression $\operatorname{sir} 2 \Delta / \Delta$ relative to $W T$

NOVEL-Ca21chrR-091 ntar_1367

NOVEL-Ca21chrR-092

NOVEL-Ca21chrR-093

NOVEL-Ca21chrR-094

TAR1

NOVEL-Ca21chrR-095

C

\section{Telomeric and Subtelomeric regions}
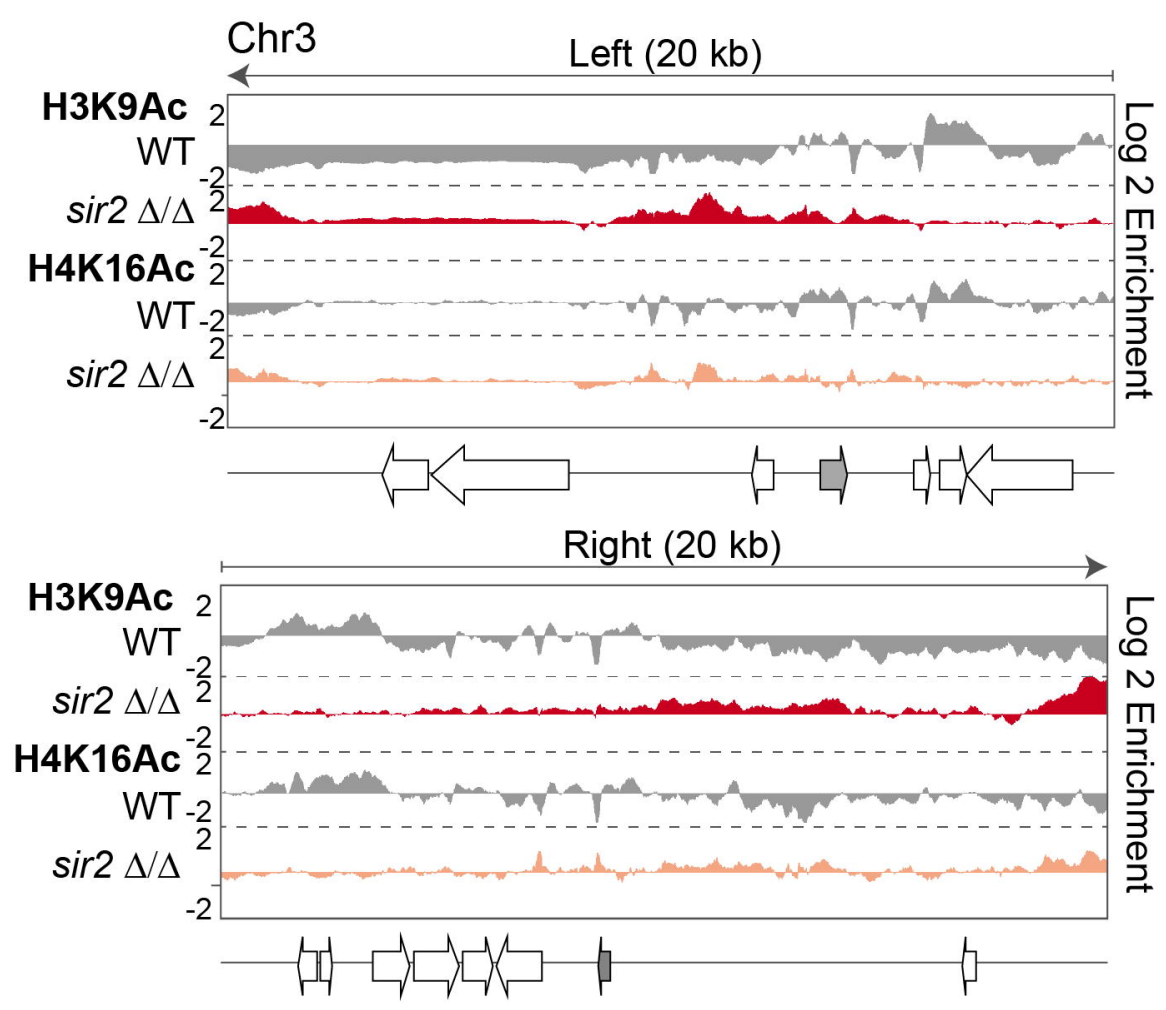

Gene Expression $\operatorname{sir} 2 \Delta / \Delta$ relative to WT

Chr

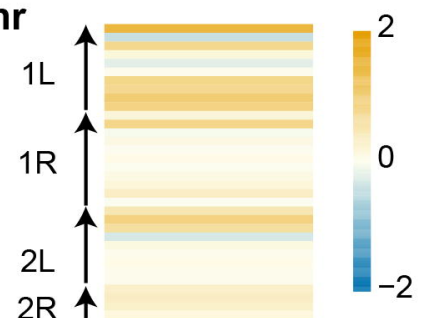

3L

3R

$4 \mathrm{~L}$

$4 \mathrm{R}$

$5 \mathrm{~L}$

$5 \mathrm{R}$

$6 \mathrm{~L}$

$6 \mathrm{R}$

$7 \mathrm{~L}$

$7 \mathrm{R}$

$\mathrm{RL} \uparrow$ 


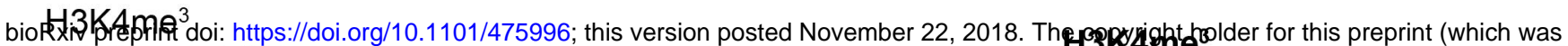
not-êt
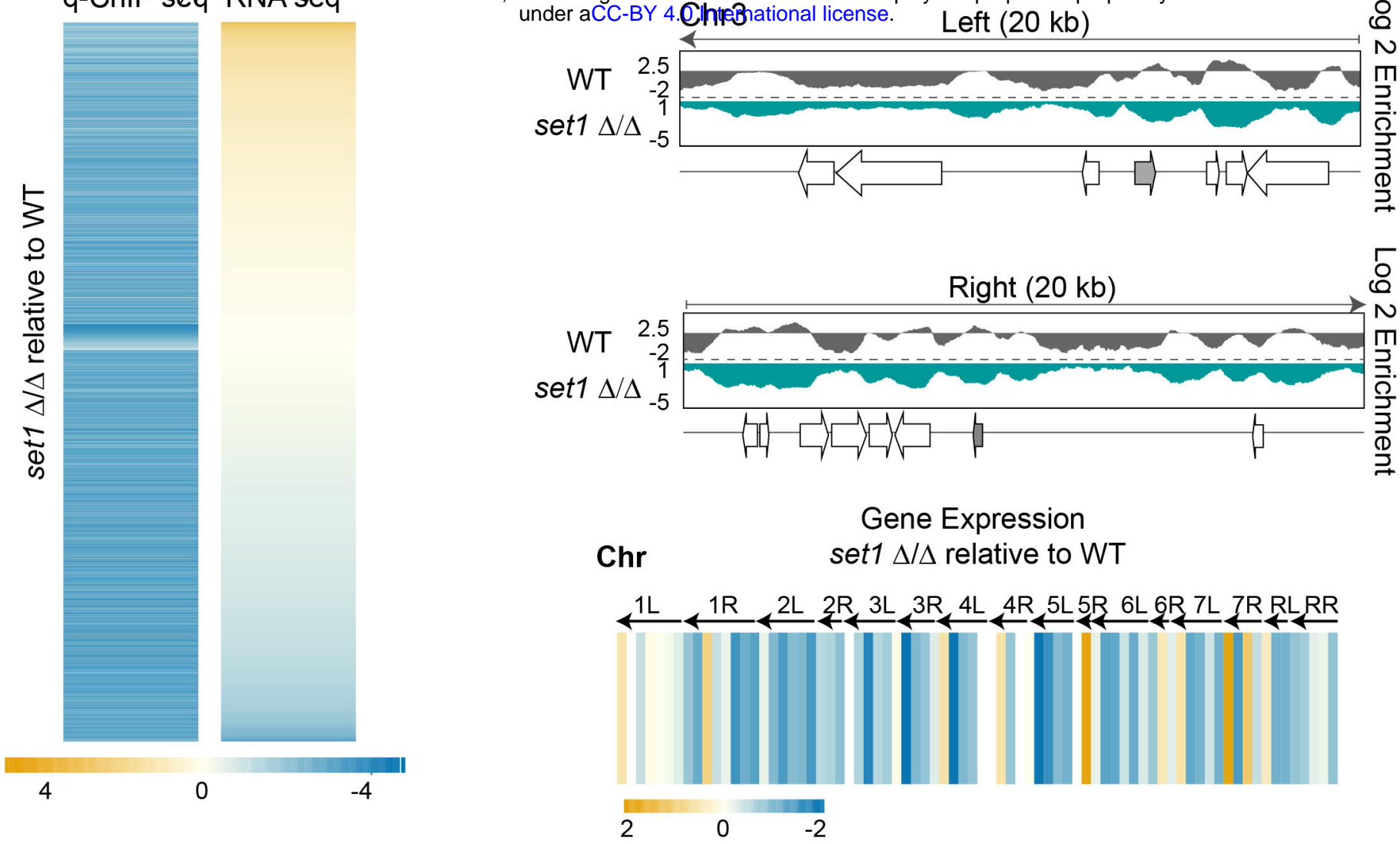

C

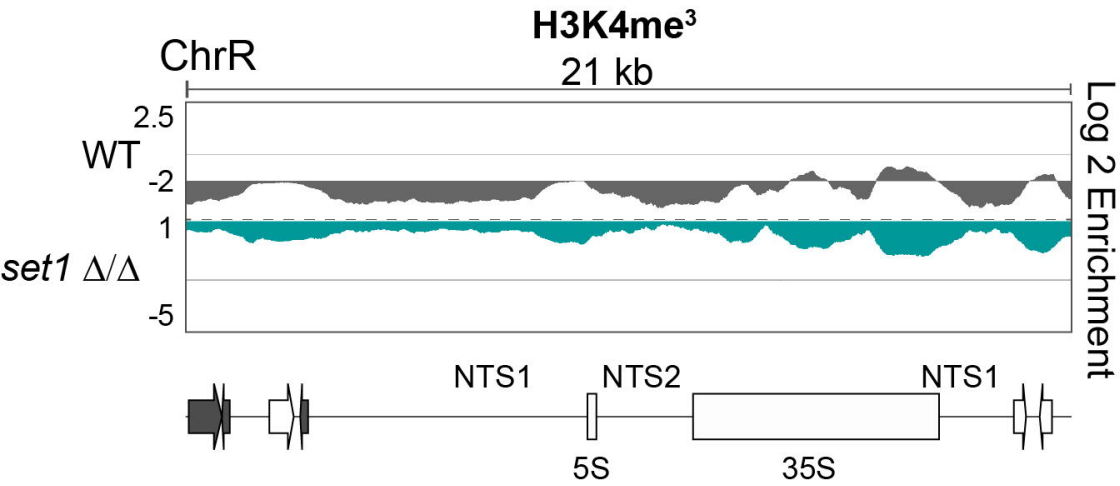

\section{Gene Expression set $1 \Delta / \Delta$ relative to WT}

NOVEL-Ca21 chrR-091

ntar_1367

NOVEL-Ca21 chrR-092

NOVEL-Ca21 chrR-093

NOVEL-Ca21 chrR-094

TAR1
D

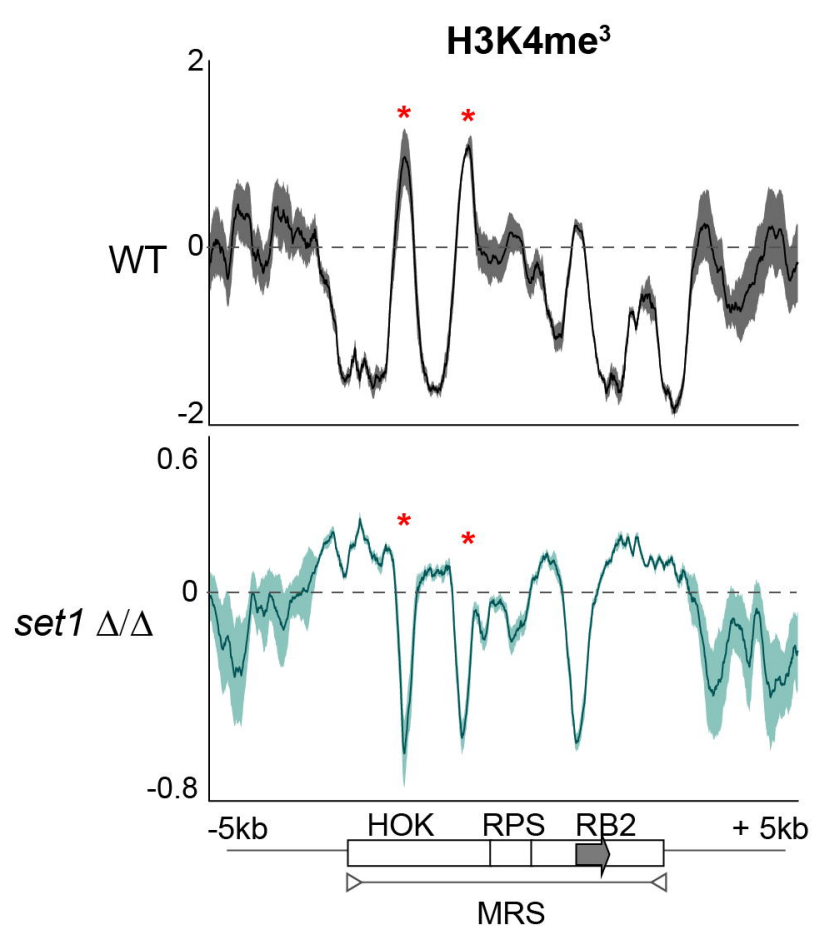

Gene Expression set1 $\Delta / \Delta$ relative to WT

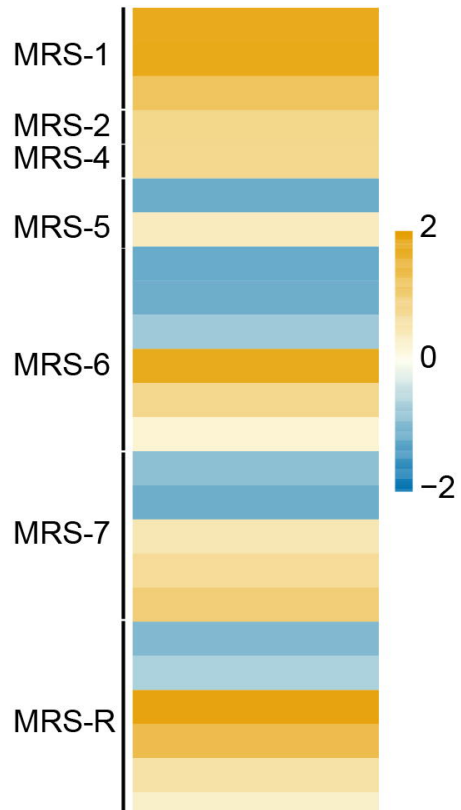

